\title{
On-Site Supramolecular Adhesion to Wet and Soft Surfaces
}

\section{via Solvent Exchange}

Changyong Cai ${ }^{\dagger}, \#$, Shuanggen $\mathrm{Wu}^{\dagger,, \#}$, Zhijian Tan ${ }^{*, *}$, Fenfang Li ${ }^{\S} \&$ Shengyi Dong ${ }^{*, \dagger}$

†College of Chemistry and Chemical Engineering, Hunan University, Changsha, Hunan 410082 , P.R. China.

Institute of Bast Fiber Crops, Chinese Academy of Agricultural Sciences, Changsha, Hunan 410205, P.R. China.

$\$$ College of Chemistry and Chemical Engineering, Central South University, Changsha, Hunan 410083, P.R. China.

${ }^{*}$ To whom correspondence should be addressed.

\#These authors contributed equally.

E-mail: dongsy@hnu.edu.cn; tanzhijian@caas.cn 
Table of Contents

1. Preparation of poly(TA-CA)s 3

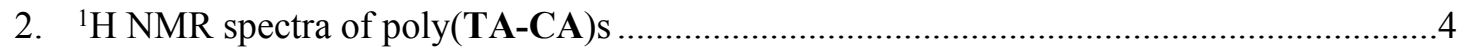

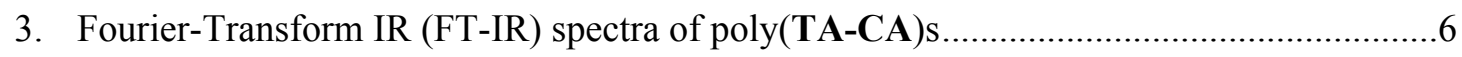

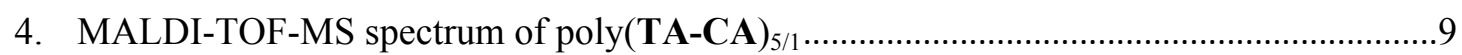

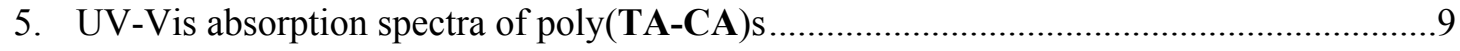

6. Powder X-Ray Diffraction (PXRD) pattern of poly(TA-CA)s........................................10

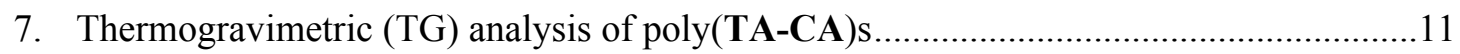

8. Differential Scanning Calorimeter (DSC) measurements of poly(TA-CA)s.....................12

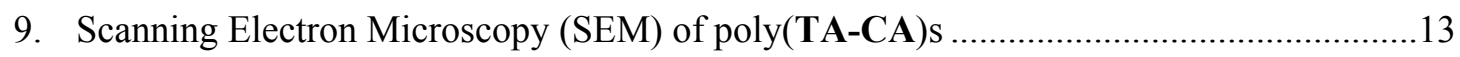

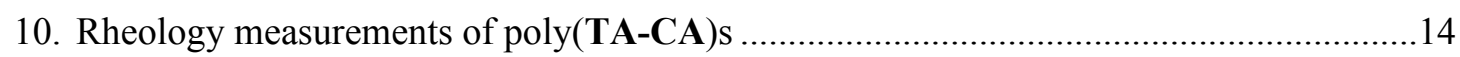

11. Environmental Scanning Electron Microscopy (ESEM) of poly(TA-CA) $)_{5 / 1} \ldots \ldots \ldots \ldots \ldots \ldots \ldots . . . .17$

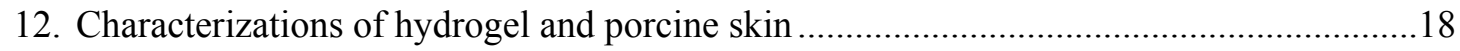

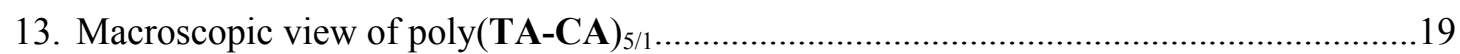

14. Stress-strain curve of poly(TA-CA $)_{5 / 1}$ and adhesion behavior after solvent exchange .....22

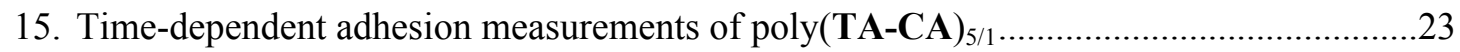

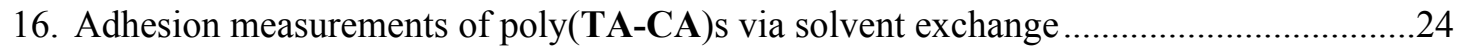

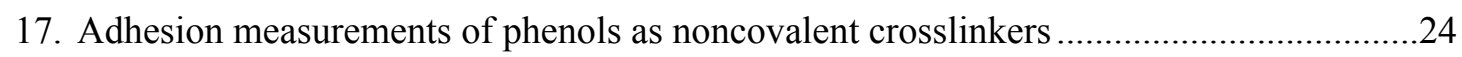

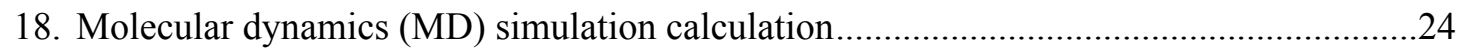

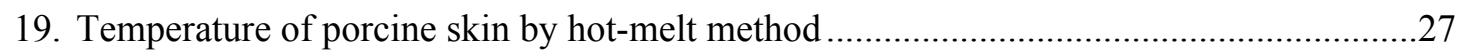

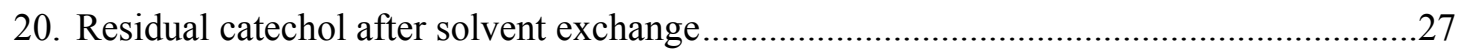

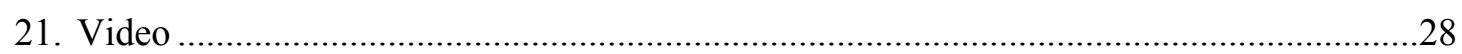

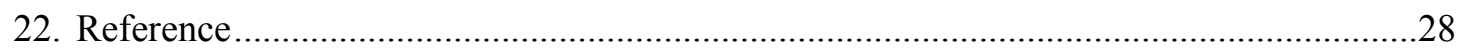




\section{Preparation of poly $(T A-C A) s$}

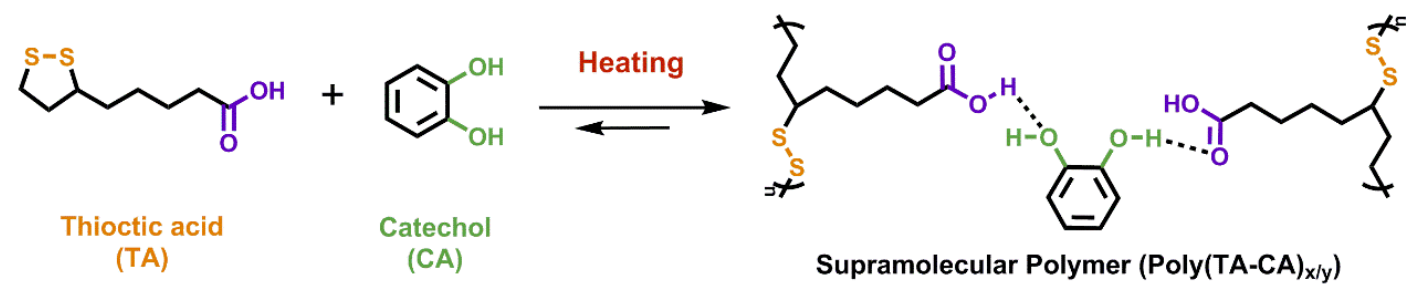

Figure S1. Synthesis route of poly(TA-CA)s.

Table S1. Poly(TA-CA)s

\begin{tabular}{|c|c|c|c|c|}
\hline Number & Component 1 & Ratio & Component 2 & Abbreviation \\
\hline 1 & & $1: 1$ & & $\operatorname{Poly}(\mathbf{T A}-\mathbf{C A})_{1 / 1}$ \\
\hline 2 & & $5: 1$ & & $\operatorname{Poly}(\text { TA-CA })_{5 / 1}$ \\
\hline 3 & Thioctic acid & $10: 1$ & Catechol & $\operatorname{Poly}(\mathbf{T A}-\mathbf{C A})_{10 / 1}$ \\
\hline 4 & (TA) & $15: 1$ & (CA) & Poly(TA-CA) ${ }_{15 / 1}$ \\
\hline 5 & & $20: 1$ & & Poly(TA-CA $)_{20 / 1}$ \\
\hline 6 & & $1: 0$ & & Poly(TA) \\
\hline
\end{tabular}

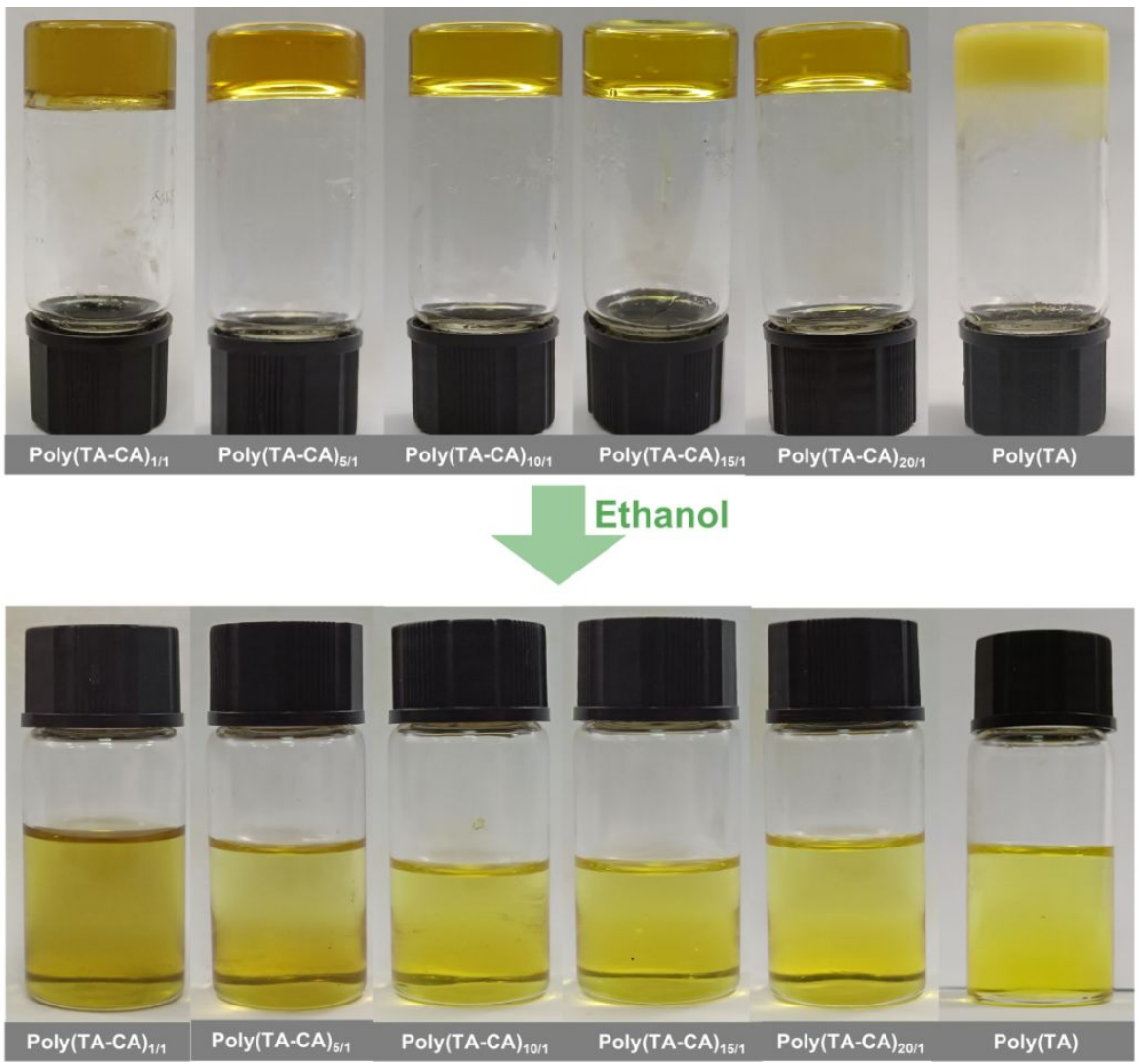

Figure S2. Poly(TA-CA)s in bulk and in ethanol (25 wt \%). 


\section{2. ${ }^{1} \mathrm{H} N M R{ }^{13} \mathrm{C} N \mathrm{NM}$ and spectra of poly $(\mathrm{TA}-\mathrm{CA}) \mathrm{s}$}

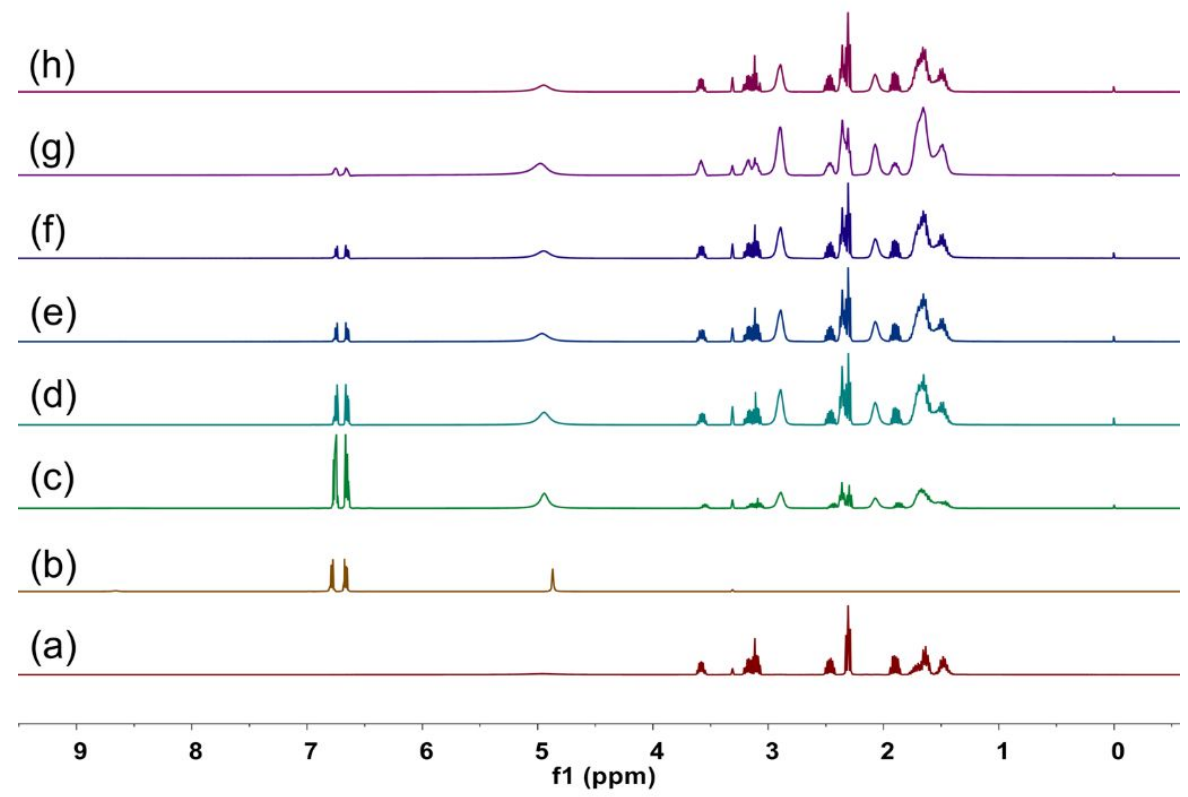

Figure S3. ${ }^{1} \mathrm{H}$ NMR spectra $\left(400 \mathrm{MHz}, \mathrm{CD}_{3} \mathrm{OD}, 100 \mathrm{mg} \mathrm{mL}^{-1} \text { ) of (a) TA, (b) CA, (c) poly(TA-CA) }\right)_{1 / 1}$, (d) poly(TACA $)_{5 / 1}$, (e) poly(TA-CA $)_{10 / 1}$, (f) poly(TA-CA $)_{15 / 1}$, (g) poly(TA-CA $)_{20 / 1}$, and (h) poly(TA) $\left(200 \mathrm{mg} \mathrm{mL}^{-1}\right.$ for TA and CA).

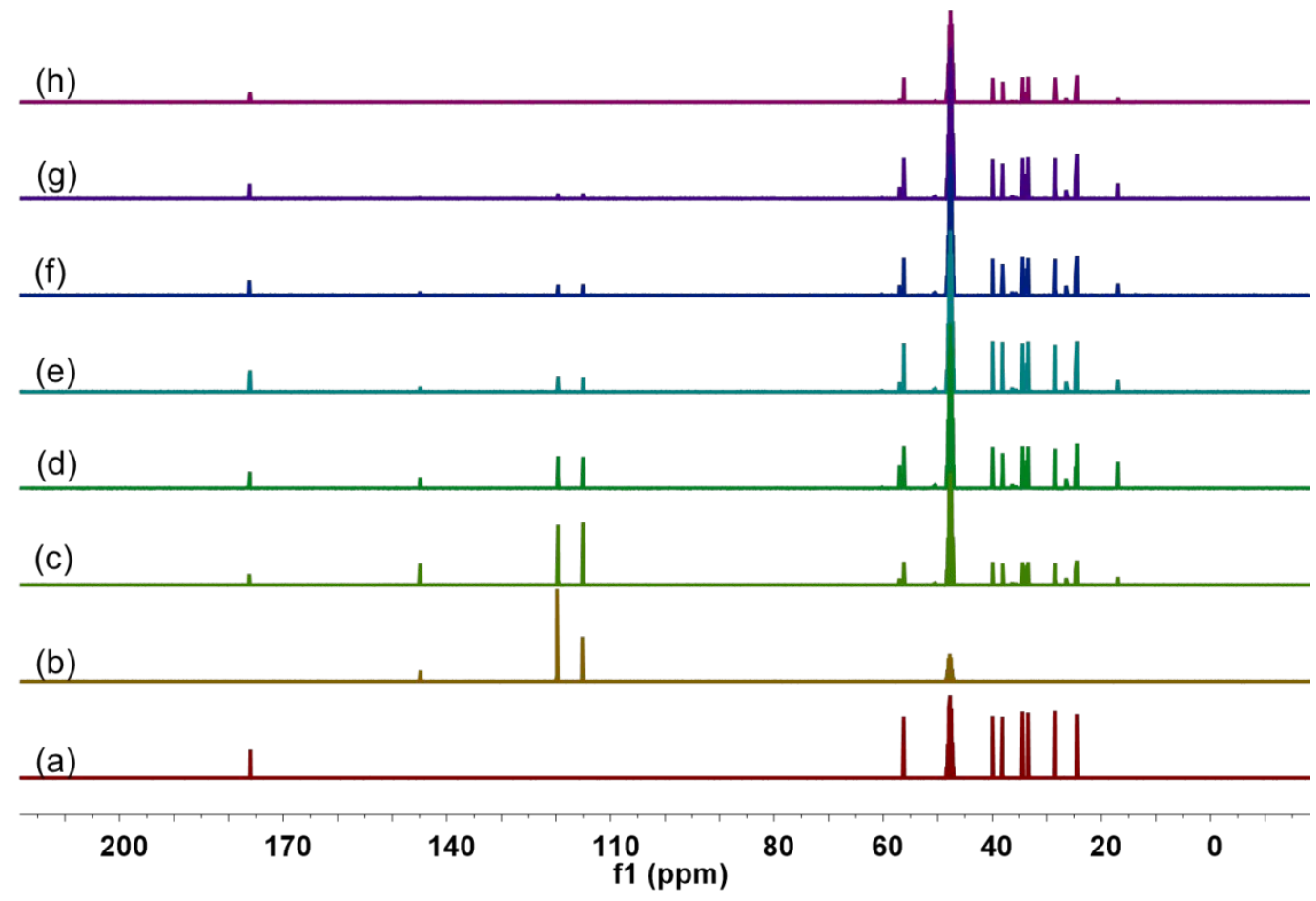

Figure S4. ${ }^{13} \mathrm{C}$ NMR spectra (400 MHz, $\mathrm{CD}_{3} \mathrm{OD}, 100 \mathrm{mg} \mathrm{mL}^{-1}$ ) of (a) TA, (b) CA, (c) poly(TA-CA) $)_{1 / 1}$, (d) poly(TACA $)_{5 / 1}$, (e) poly(TA-CA $)_{10 / 1}$, (f) poly(TA-CA $)_{15 / 1}$, (g) poly(TA-CA $)_{20 / 1}$, and (h) poly(TA) $\left(200 \mathrm{mg} \mathrm{mL}^{-1}\right.$ for TA and CA). 


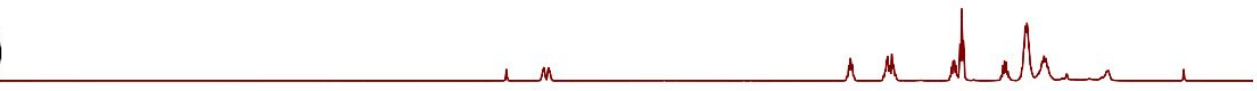

(e)

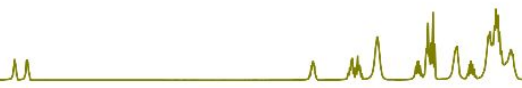

(d) Mndm

(c) n maldon

(b) uallus

(a) adicula

\begin{tabular}{llllllllllllll}
\hline 13 & 12 & 11 & 10 & 9 & 8 & $7 \underset{\mathrm{f} 1(\mathrm{ppm})}{6}$ & 5 & 4 & 3 & 2 & 1 & 0
\end{tabular}

Figure S5. ${ }^{1} \mathrm{H}$ NMR spectra (400 MHz, $100 \mathrm{mg} \mathrm{mL}^{-1}$, room temperature) of poly(TA-CA) $)_{5 / 1}$ in (a) $\mathrm{CD}_{3} \mathrm{OD}$, (b) $\mathrm{CD}_{3} \mathrm{CD}_{2} \mathrm{OD}$, (c) $\mathrm{CD}_{3} \mathrm{SOCD}_{3}$, (d) $\mathrm{CD}_{3} \mathrm{CN}$, (e) $\mathrm{CD}_{3} \mathrm{COCD}_{3}$, and (f) $\mathrm{CDCl}_{3}$.

(b)

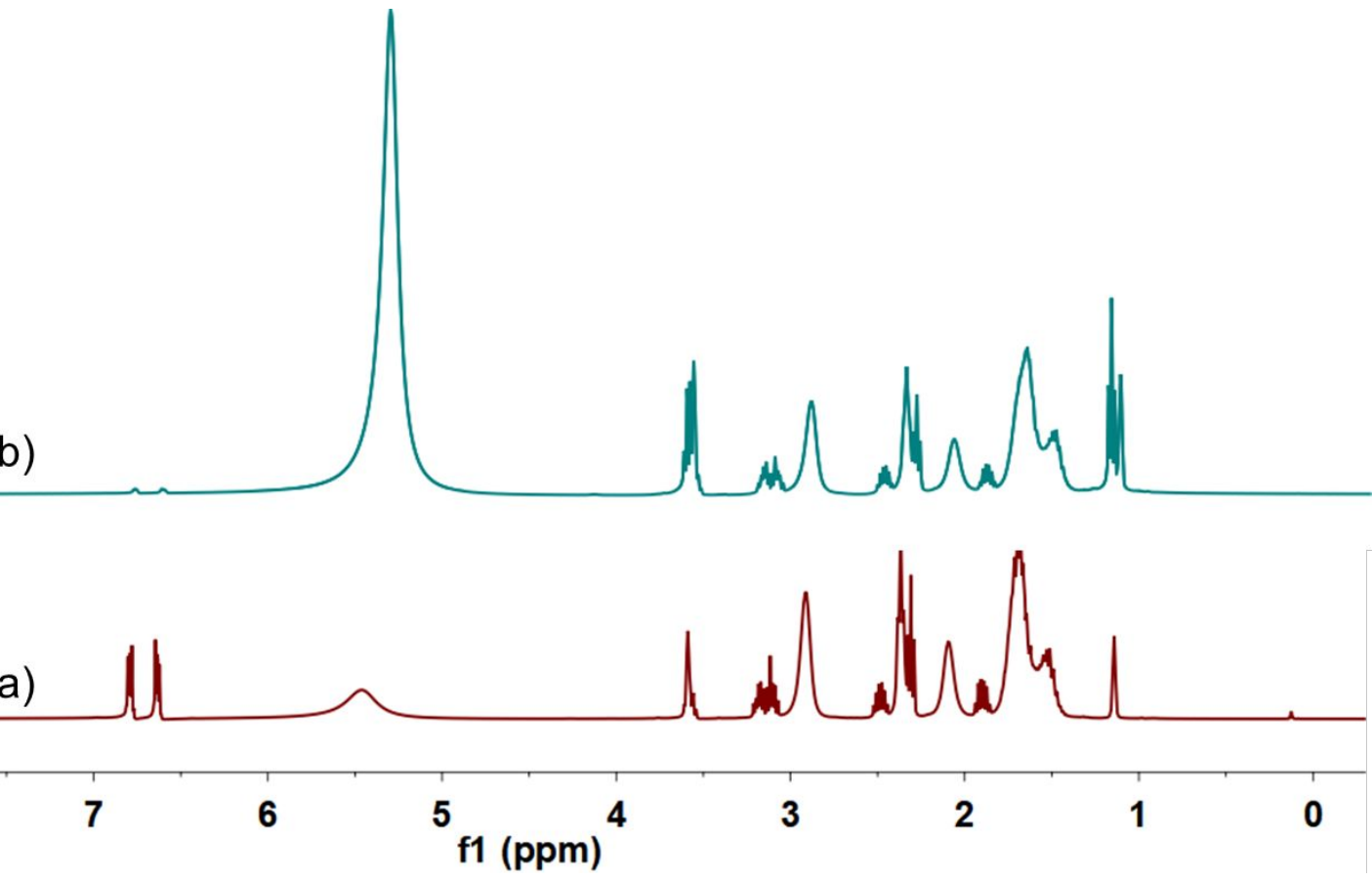

Figure S6. ${ }^{1} \mathrm{H}$ NMR spectra (400 MHz, $\mathrm{CD}_{3} \mathrm{CD}_{2} \mathrm{OD}$, room temperature) of (a) poly(TA-CA) $)_{5 / 1}$ and (b) poly(TACA $)_{5 / 1}$ after ethanol-water exchange $\left(100 \mathrm{mg} \mathrm{mL}^{-1}\right.$ for (a) and $50 \mathrm{mg} \mathrm{mL}^{-1}$ for (b)). 


\section{Fourier-Transform IR (FT-IR) spectra of poly(TA-CA)s}

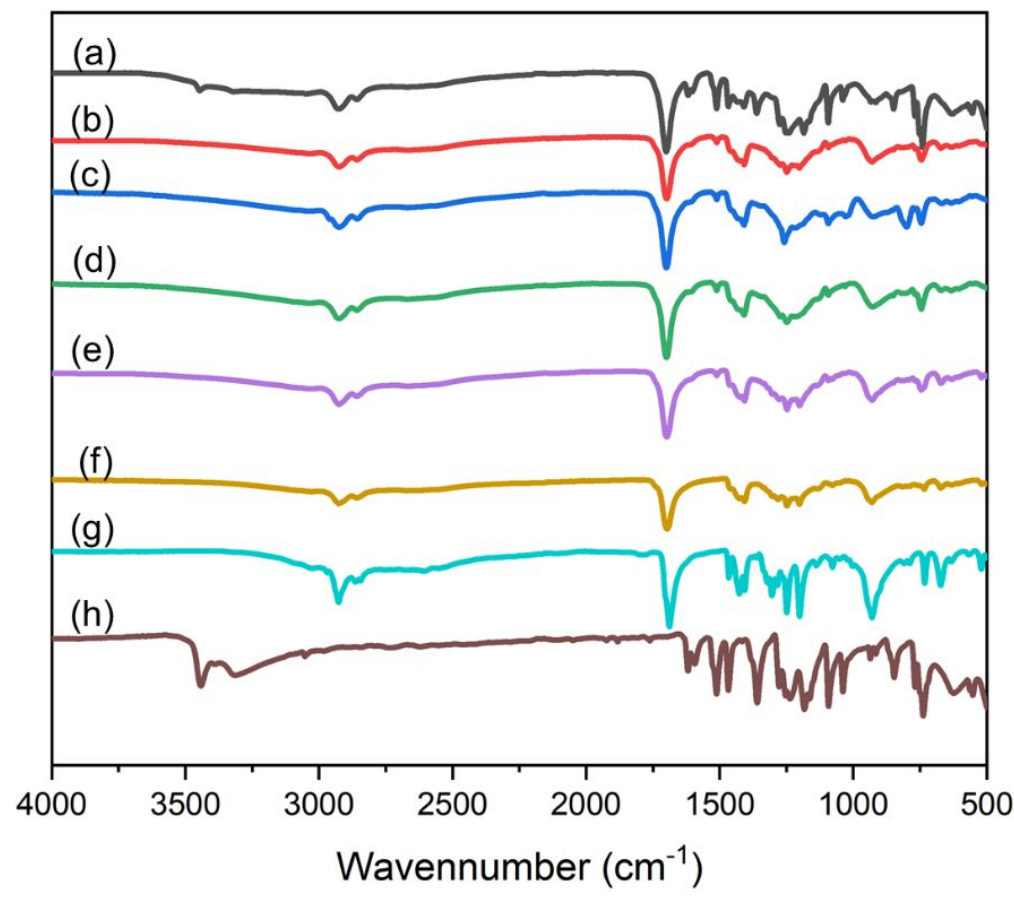

Figure S7. FT-IR spectra of poly(TA-CA)s in bulk: (a) poly(TA-CA) $)_{1 / 1}$; (b) poly(TA-CA) $)_{5 / 1}$; (c) poly(TA-CA) (10/1 $_{\text {; }}$; (d) $\operatorname{poly}(\text { TA-CA) })_{15 / 1}$; (e) $\operatorname{poly}(\text { TA-CA })_{20 / 1}$; (f) poly(TA); (g) TA; (h) CA.

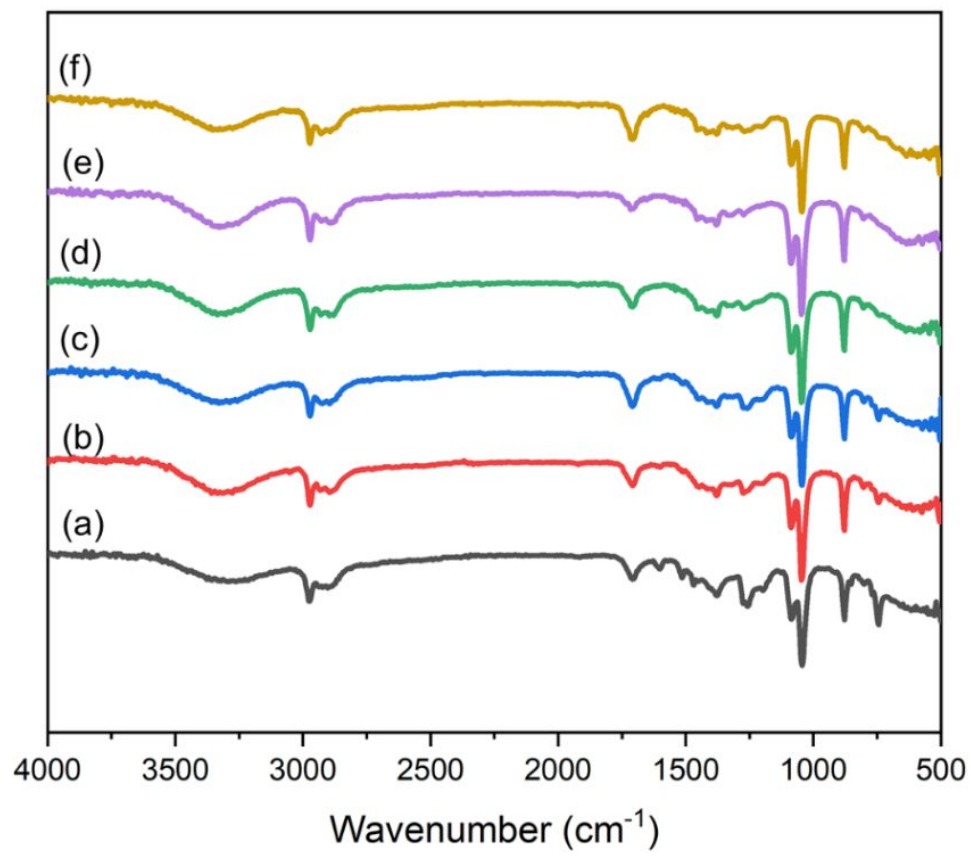

Figure S8. FT-IR spectra of poly(TA-CA)s in ethanol: (a) poly(TA-CA $)_{1 / 1}$; (b) $\operatorname{poly}(\mathbf{T A}-\mathbf{C A})_{5 / 1}$; (c) poly(TACA) $)_{10 / 1}$; (d) $\operatorname{poly}(\text { TA-CA })_{15 / 1}$; (e) poly(TA-CA) $)_{20 / 1}$; (f) poly(TA). 


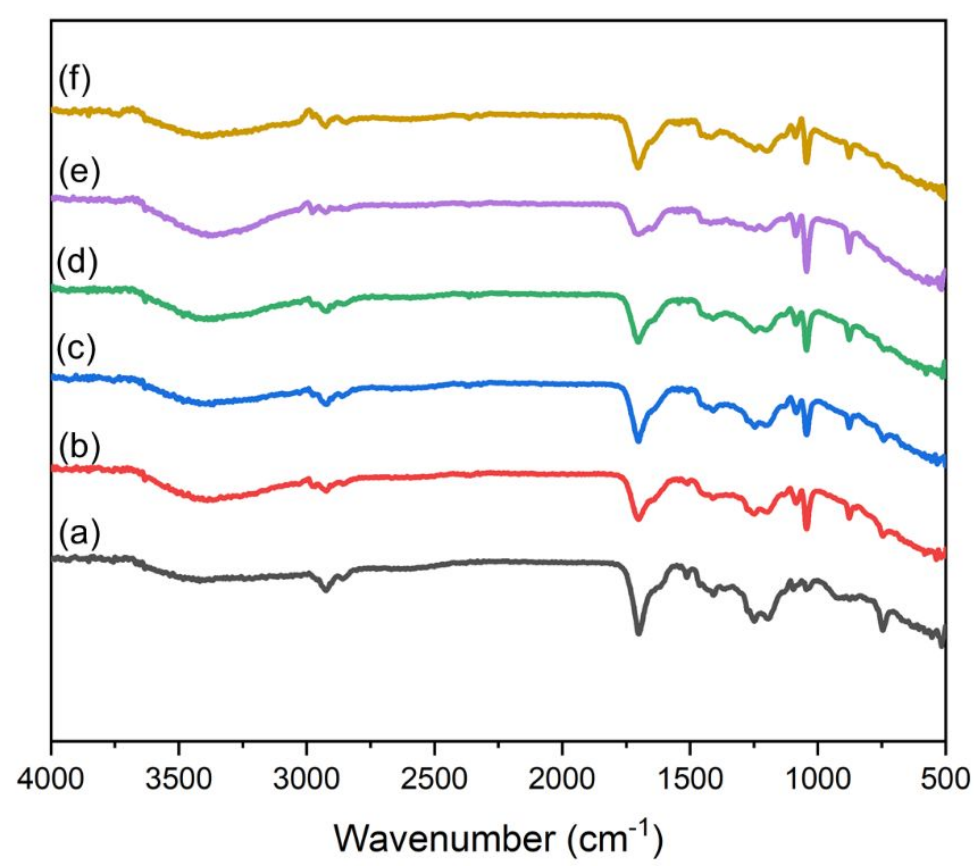

Figure S9. FT-IR spectra of poly(TA-CA)s after ethanol-water exchange: (a) poly(TA-CA) $)_{1 / 1}$; (b) poly(TA-CA) $)_{5 / 1}$; (c) $\operatorname{poly}(\mathbf{T A}-\mathbf{C A})_{10 / 1}$; (d) $\operatorname{poly}(\mathbf{T A}-\mathbf{C A})_{15 / 1}$; (e) $\operatorname{poly}(\mathbf{T A}-\mathbf{C A})_{20 / 1}$; (f) poly(TA).

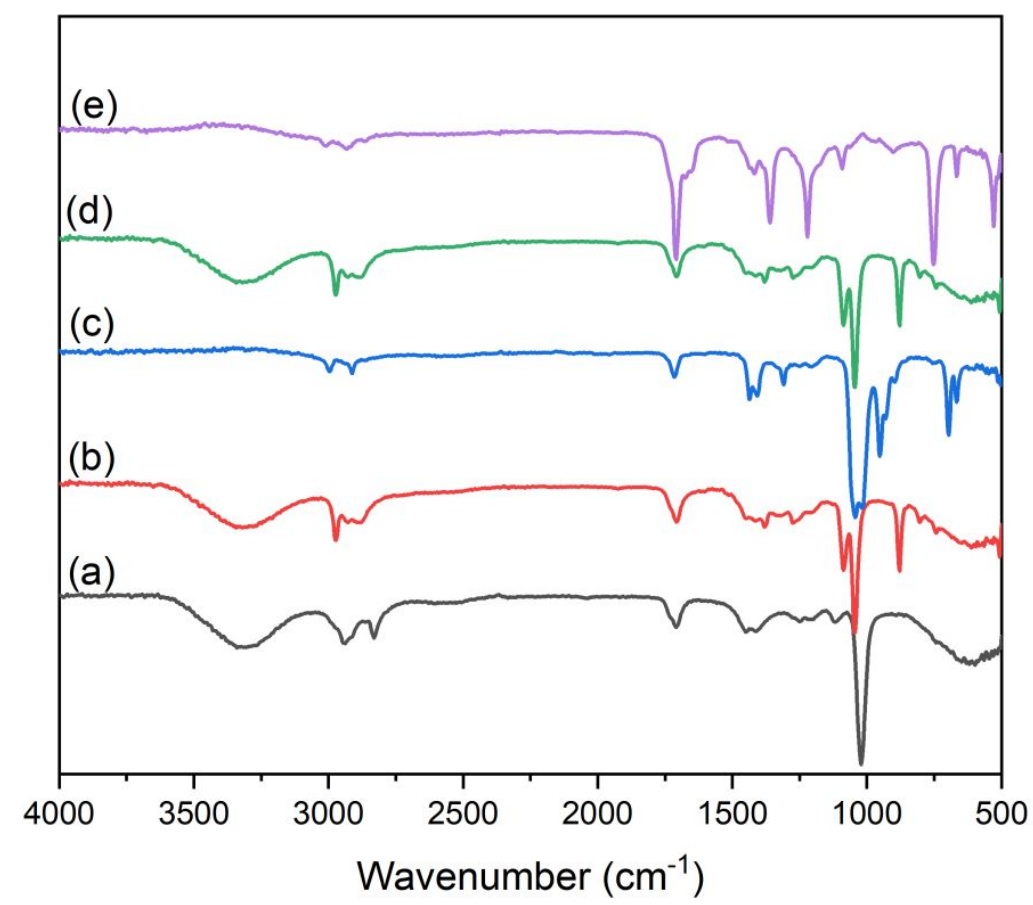

Figure S10. FT-IR spectra of poly(TA-CA) $)_{5 / 1}$ in different solvents: (a) methanol; (b) ethanol; (c) DMSO; (d) acetonitrile; (e) acetone. 


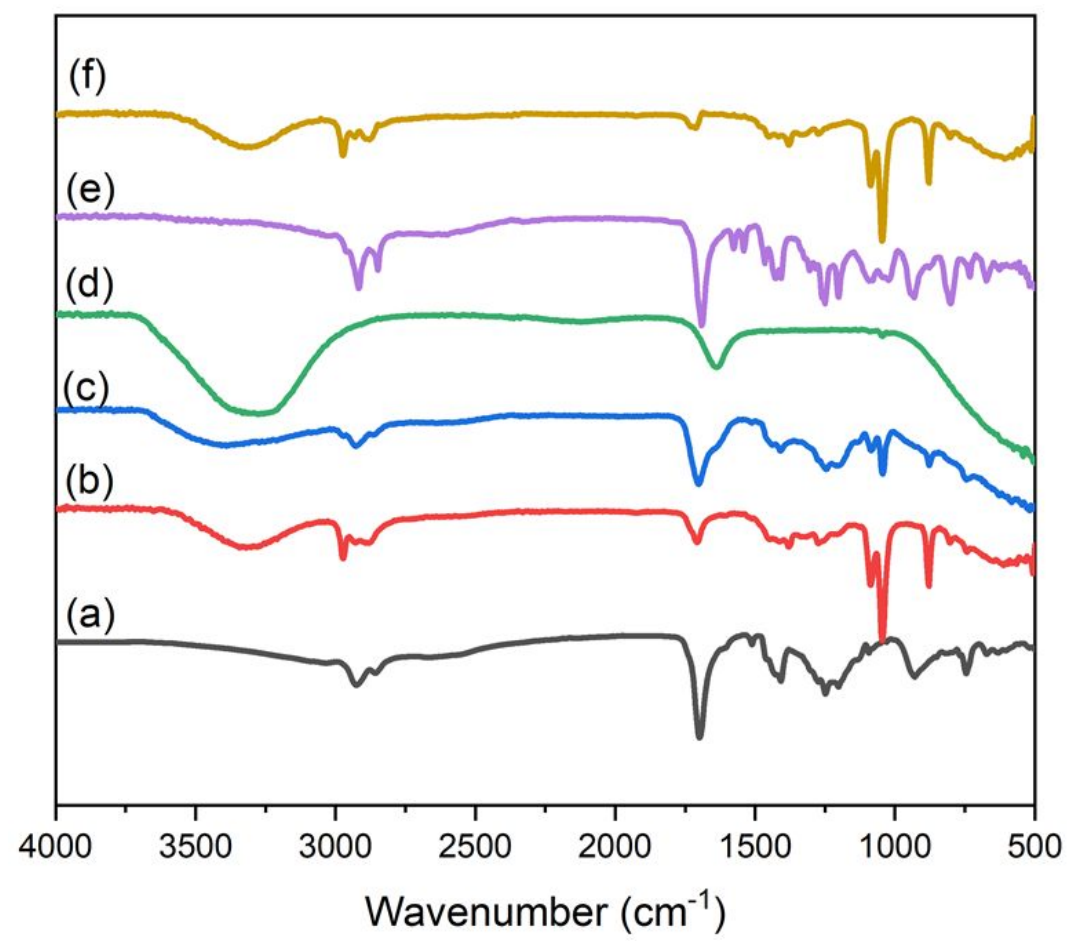

Figure S11. FT-IR spectra of (a) poly(TA-CA) $)_{5 / 1}$, (b) poly(TA-CA) $)_{5 / 1}$ in ethanol, (c) poly(TA-CA) $)_{5 / 1}$ after solvent exchange, (d) the residual solution (after ethanol-water exchange), (e) poly(TA-CA) $)_{5 / 1}$ after solvent exchange (dried), and (f) the residual solution after ethanol-water exchange (dried).

Here "dried" indicates the sample was dried and the solvent was removed.

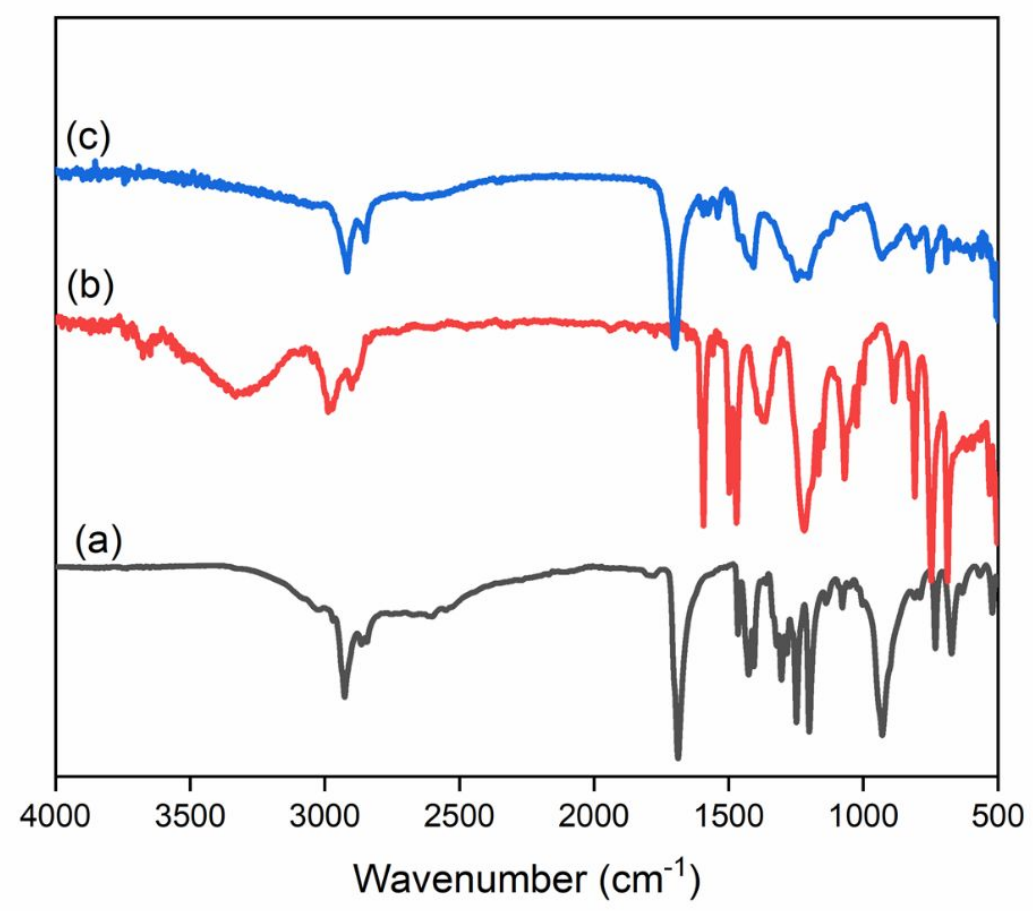

Figure S12. FT-IR spectra of (a) TA, (b) phenol, and (c) poly(TA-phenol) $)_{5 / 1}$. 


\section{MALDI-TOF-MS spectrum of poly $(T A-C A)_{5 / 1}$}

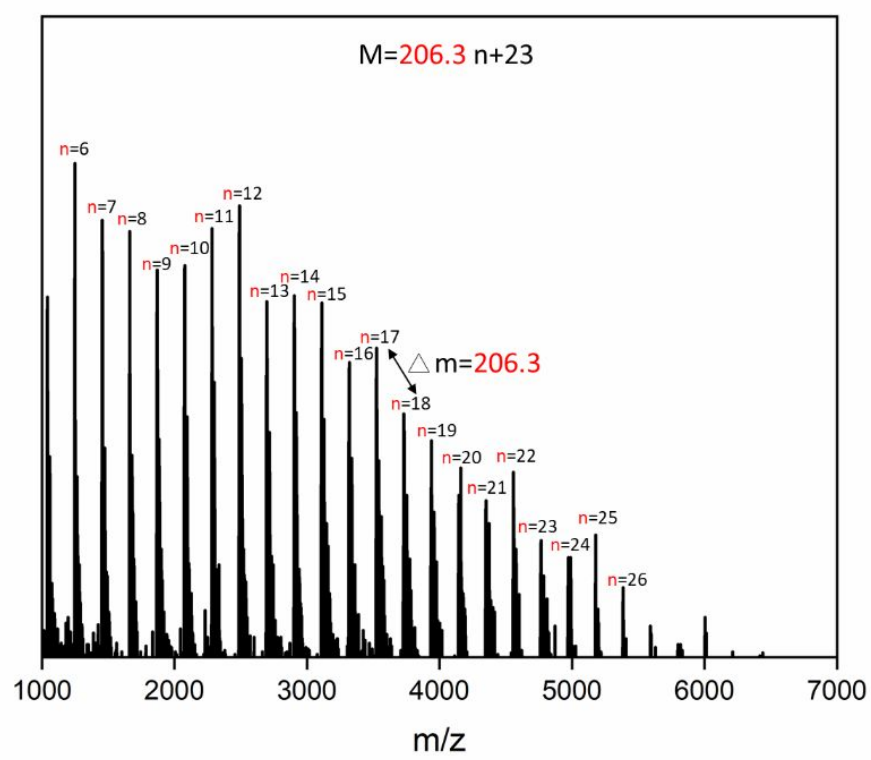

Figure S13. MALDI-TOF-MS spectrum of poly(TA-CA $)_{5 / 1}$.

As shown in Figure S13, only peaks assigned to poly(TA) were observed, indicating that poly(TA-CA $)_{5 / 1}$ is a homopolymer and the cross-linking between poly(TA) and catechol was non-covalent. As suggested by reported work, TA favors to form cyclic polymers instead of linear polymers. ${ }^{1,2}$

\section{UV-Vis absorption spectra of poly $(T A-C A) s$}

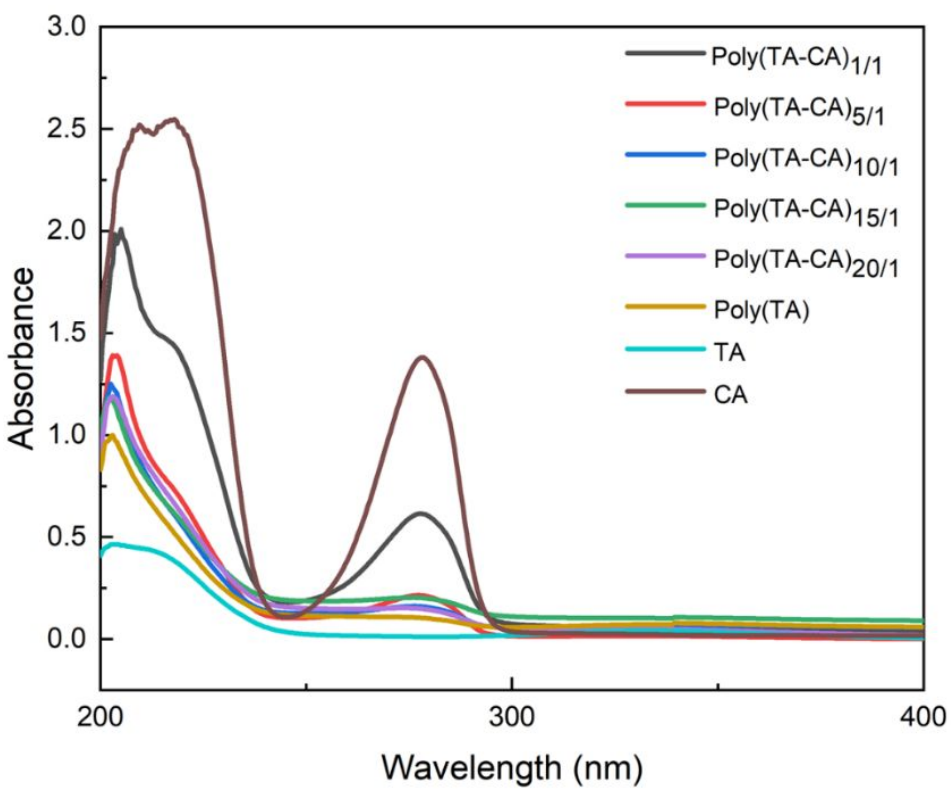

Figure S14. UV-Vis absorption spectra of CA, TA, poly(TA), and poly(TA-CA)s in ethanol $\left(0.1 \mathrm{mg} \mathrm{mL}^{-1}\right)$. 
6. Powder X-Ray Diffraction (PXRD) pattern of poly(TA-CA)s

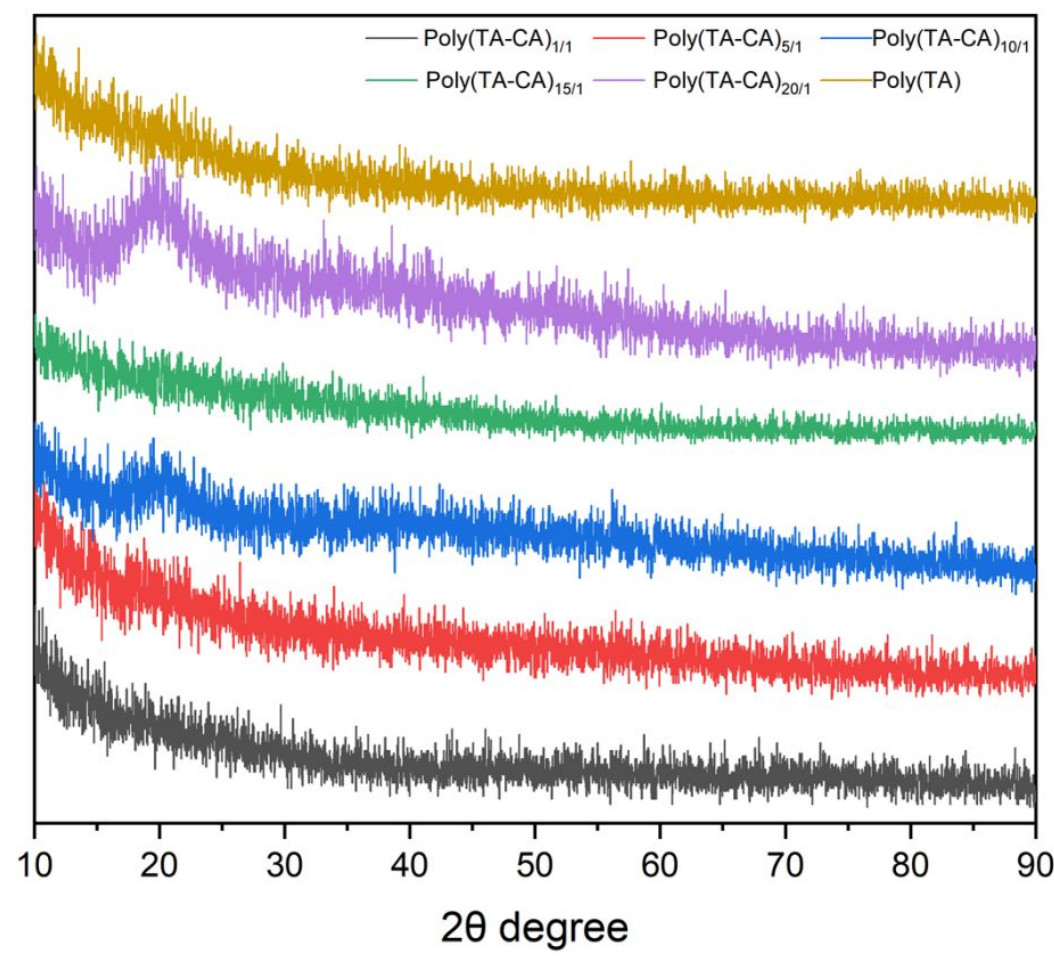

Figure S15. PXRD spectra of poly(TA-CA)s. 


\section{Thermogravimetric (TG) analysis of poly (TA-CA)s}

(a)

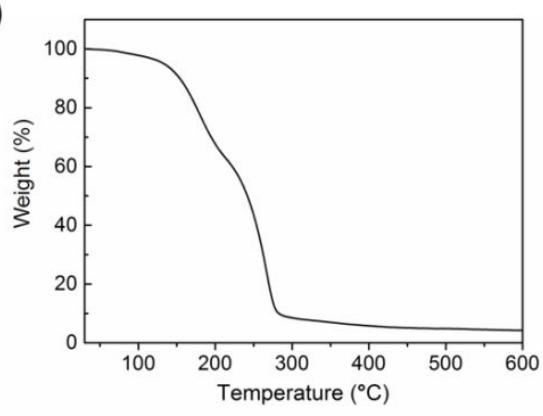

(c)

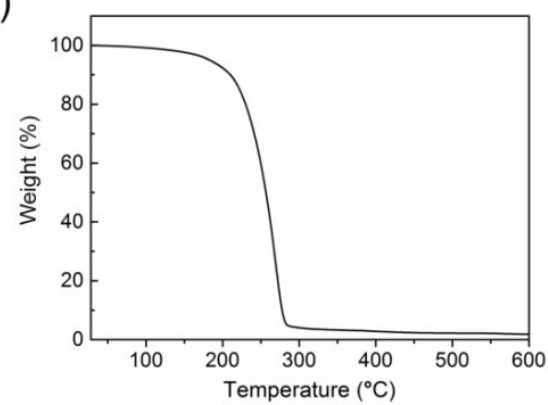

(e)

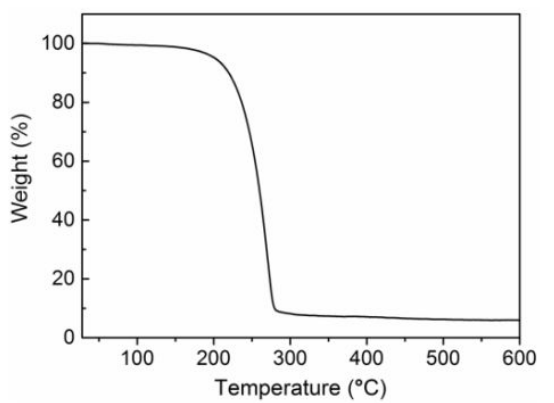

(b)

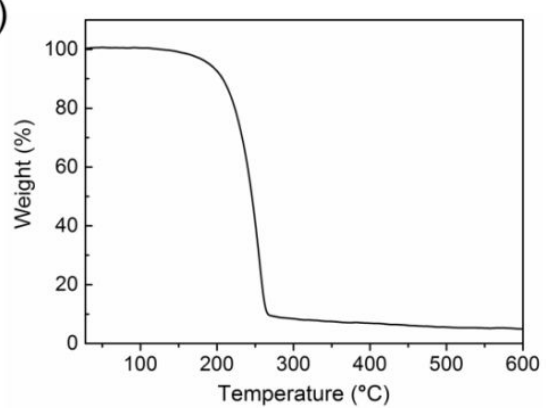

(d)

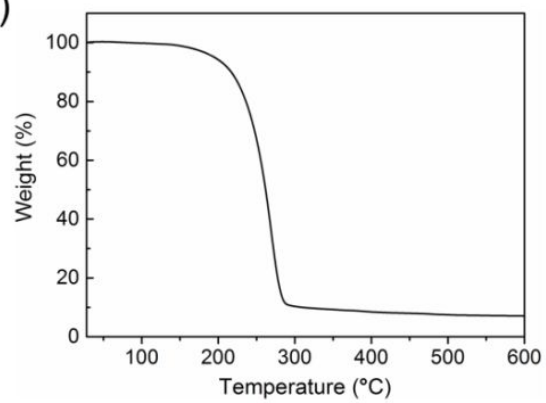

(f)

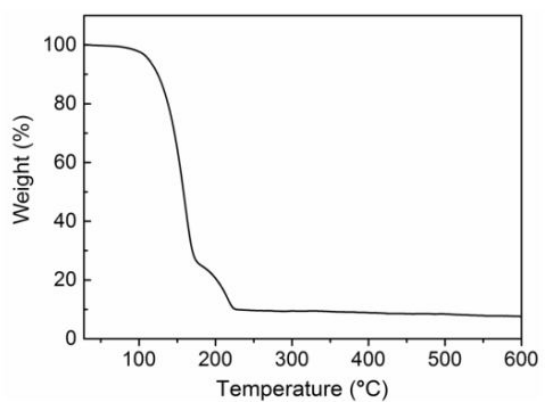

Figure S16. TG spectra of poly(TA-CA)s: (a) poly(TA-CA $)_{1 / 1}$; (b) poly(TA-CA $)_{5 / 1}$; (c) poly(TA-CA) $)_{10 / 1}$; (d) poly(TA-CA $)_{15 / 1}$; (e) poly(TA-CA $)_{20 / 1}$; (f) poly(TA).

The addition of CA can effectively enhance the thermal stability of poly(TA)

(a)

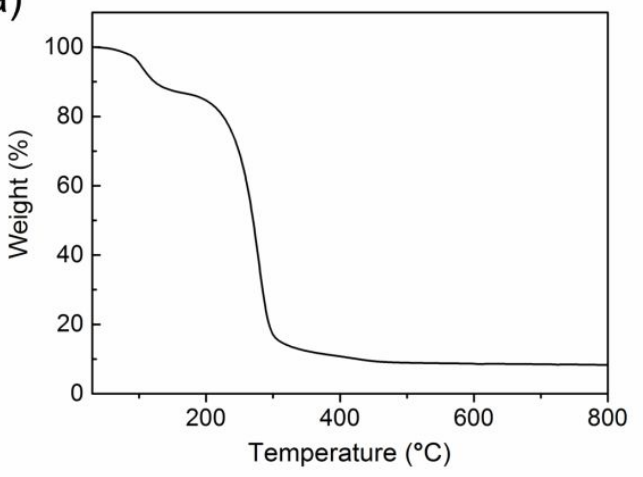

(b)

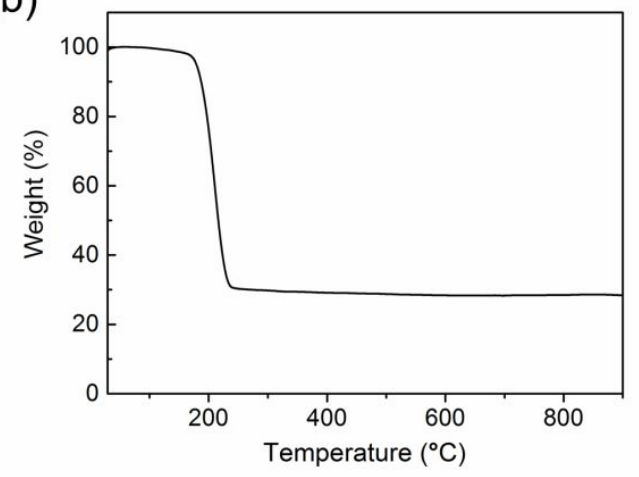

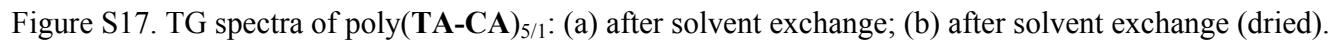


Here "dried" indicates the sample was dried and the solvent was removed. From TG results, it is demonstrated that poly(TA-CA) $)_{5 / 1}$ exhibited good thermal stability after solvent exchange.

(a)

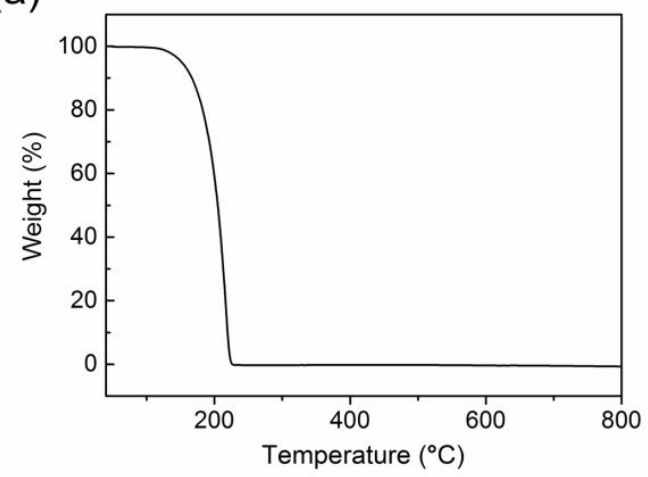

(b)

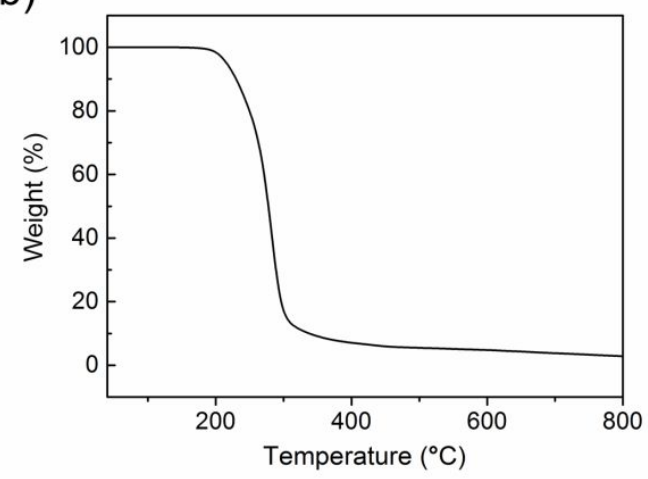

Figure S18. TG spectra of (a) CA and (b) TA.

\section{Differential Scanning Calorimeter (DSC) measurements of poly (TA-CA)s}

(a)

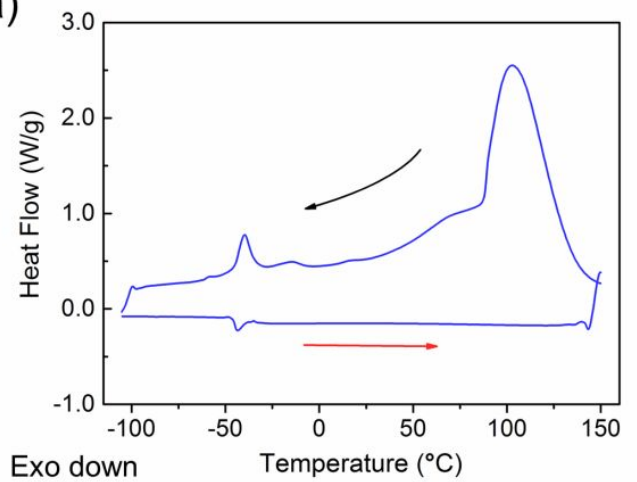

(b)

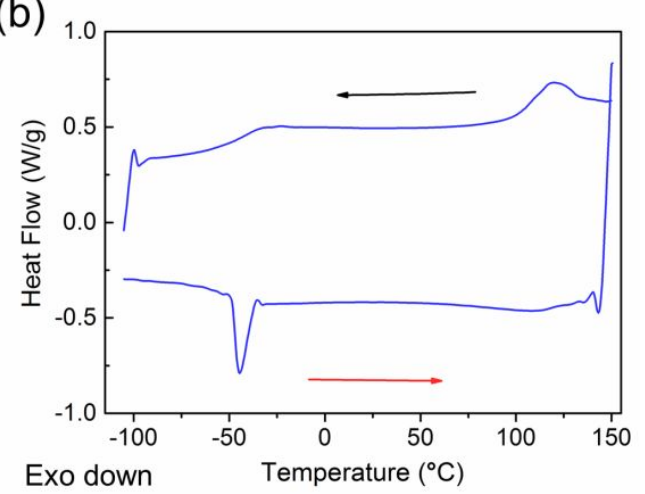

Figure S19. DSC spectra of poly(TA-CA) $)_{5 / 1}$ : (a) after solvent exchange; (b) after solvent exchange (dried).

Here "dried" indicated the sample was dried and the solvent was removed.

(a)

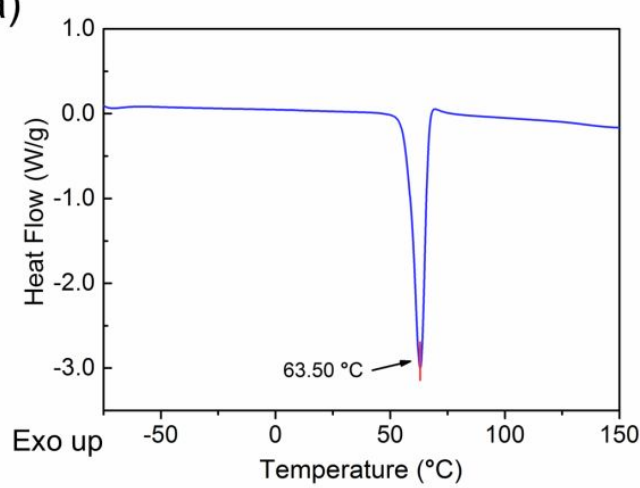

(b)

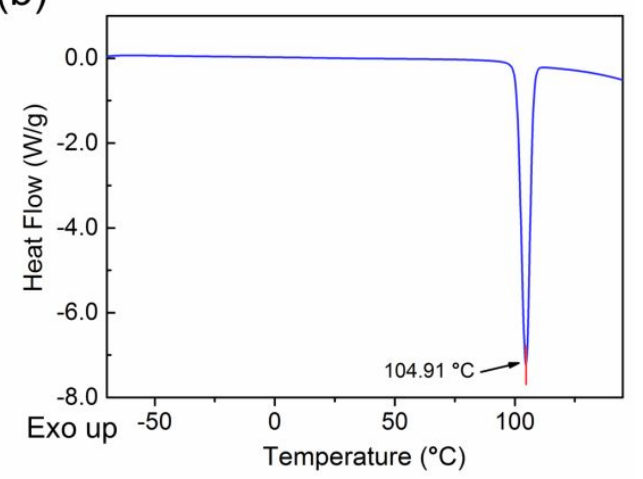

Figure S20. DSC spectra of (a) TA and (b) CA. 


\section{Scanning Electron Microscopy (SEM) of poly(TA-CA)s}

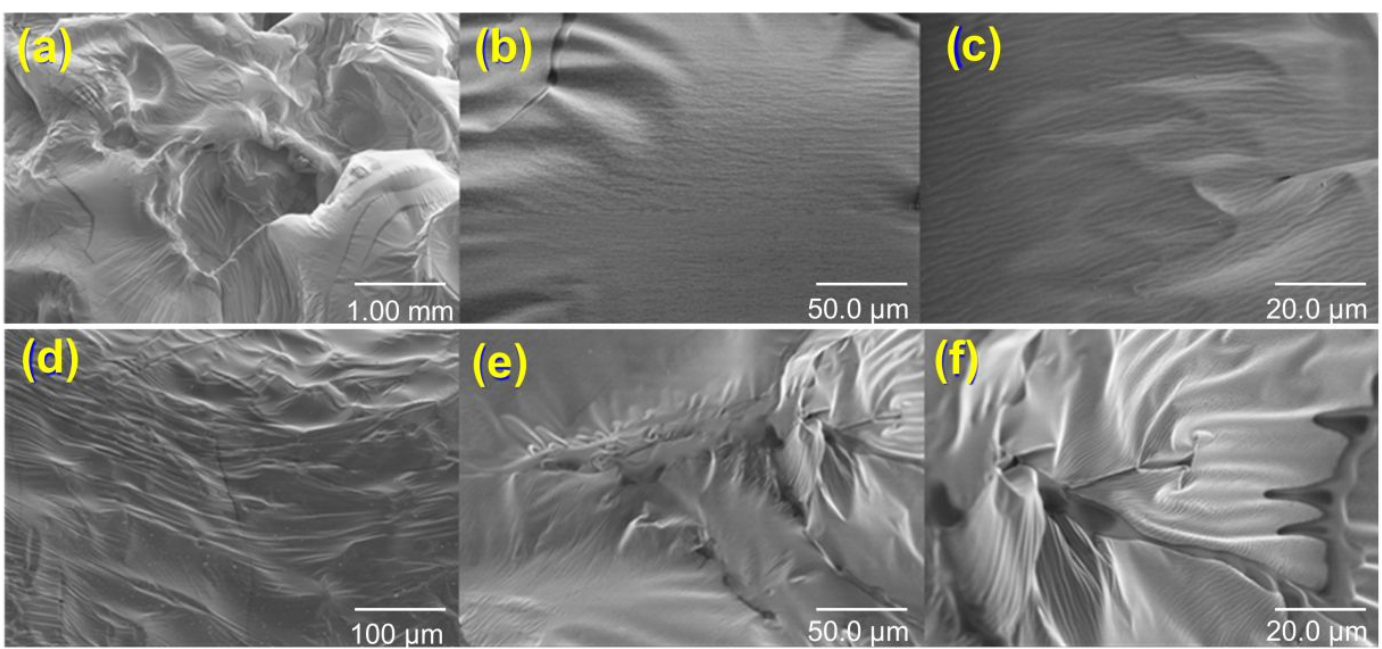

Figure S21. SEM images of $(\mathrm{a}-\mathrm{c})$ poly(TA-CA $)_{5 / 1}$ and $(\mathrm{d}-\mathrm{f})$ poly(TA).

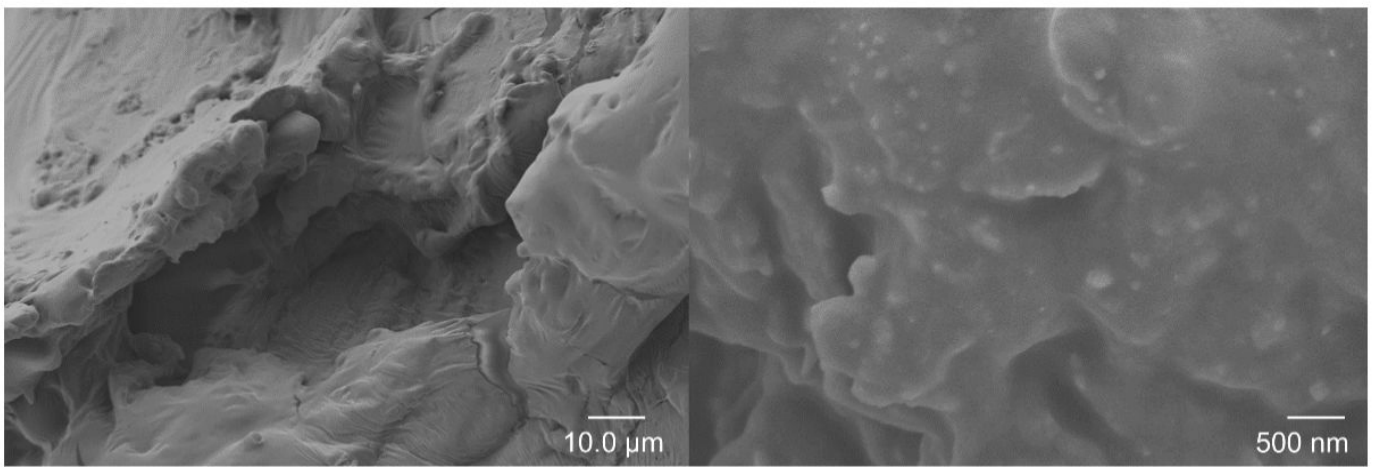

Figure S22. SEM images of poly(TA-CA) $)_{5 / 1}$ after solvent exchange (ethanol-water).

Here "dried" indicated the sample was dried and the solvent was removed. 


\section{Rheology measurements of poly $(T A-C A) s$}

(a)

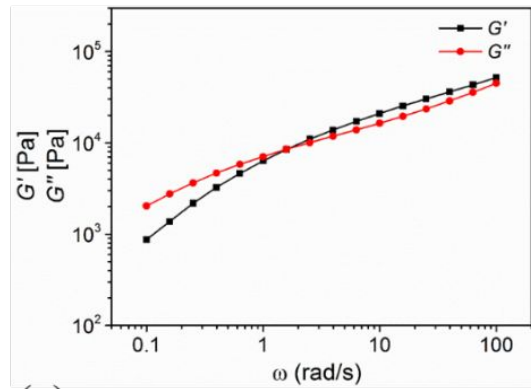

(c)

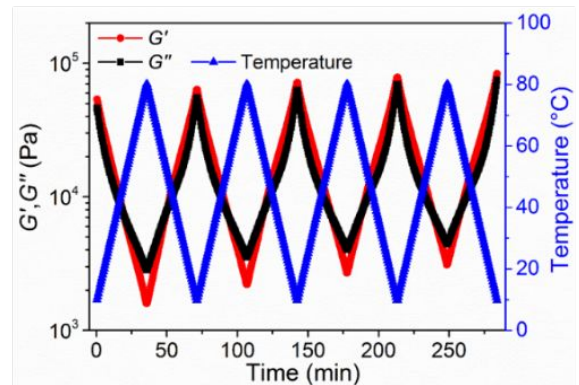

(b)

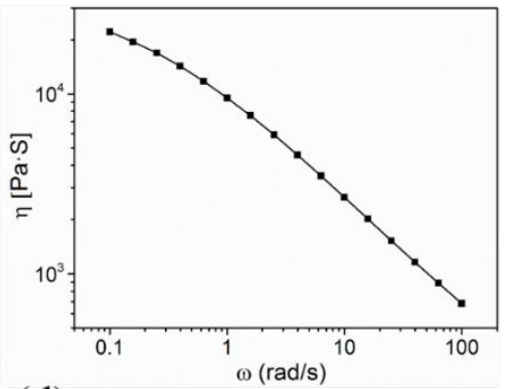

(d)

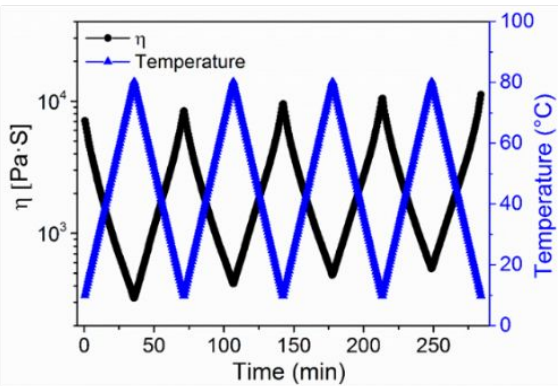

Figure S23. (a) Storage modulus $\left(G^{\prime}\right)$ and loss modulus $\left(G^{\prime} \text { ') values of poly(TA-CA }\right)_{1 / 1}$ on frequency sweep at 25 ${ }^{\circ} \mathrm{C}$; (b) composite viscosity $(\eta)$ value of poly(TA-CA $)_{1 / 1}$ on frequency sweep at $25^{\circ} \mathrm{C}$; (c) $G$ ' and $G$,' values of poly(TA-CA $)_{1 / 1}$ at reversible temperature-dependent rheological tests; (d) $\eta$ value of poly(TA-CA $)_{1 / 1}$ at reversible temperature-dependent rheological tests.

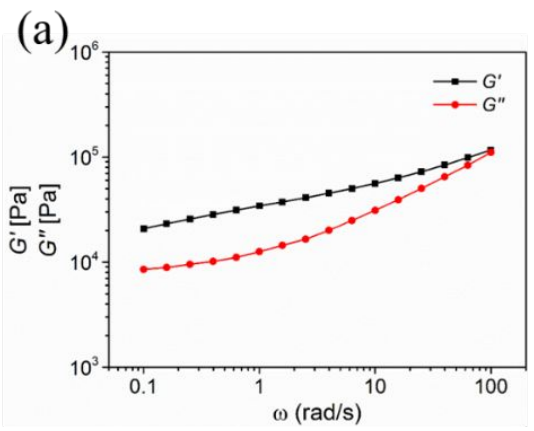

(c)

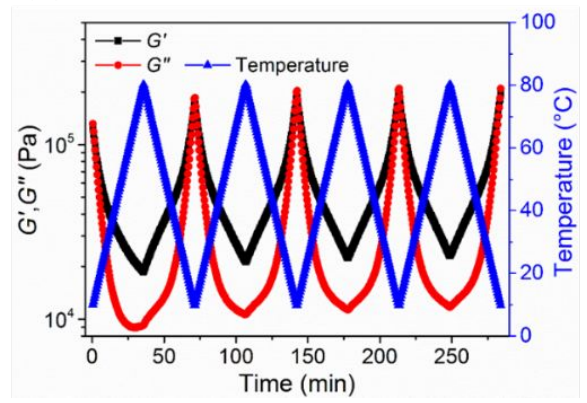

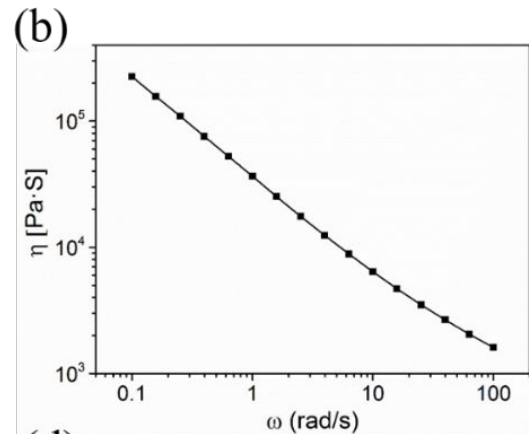

(d)

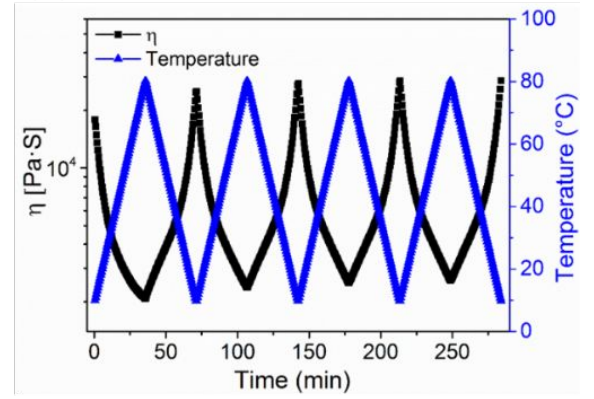

Figure S24. (a) Storage modulus $\left(G^{\prime}\right)$ and loss modulus $\left(G^{\prime} \text { ') values of poly(TA-CA }\right)_{5 / 1}$ on frequency sweep at 25 ${ }^{\circ} \mathrm{C}$; (b) composite viscosity $(\eta)$ value of poly(TA-CA $)_{5 / 1}$ on frequency sweep at $25{ }^{\circ} \mathrm{C}$; (c) $G$ ' and $G$, ' values of poly(TA-CA $)_{5 / 1}$ at reversible temperature-dependent rheological tests; (d) $\eta$ value of poly(TA-CA $)_{5 / 1}$ at reversible temperature-dependent rheological tests. 
(a)

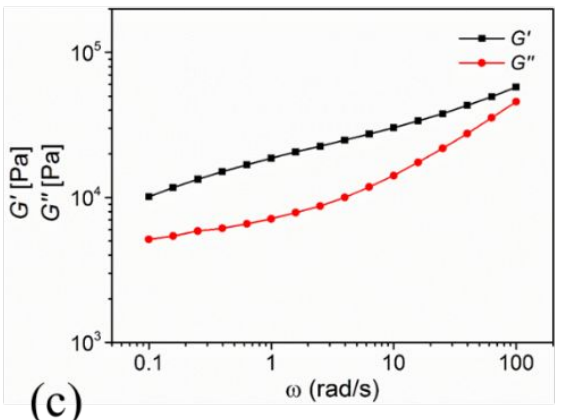

(c)

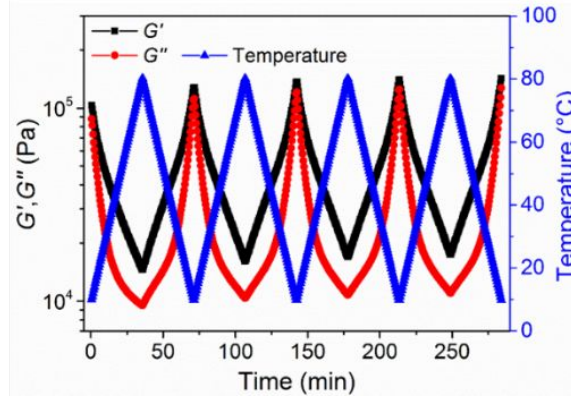

(b)
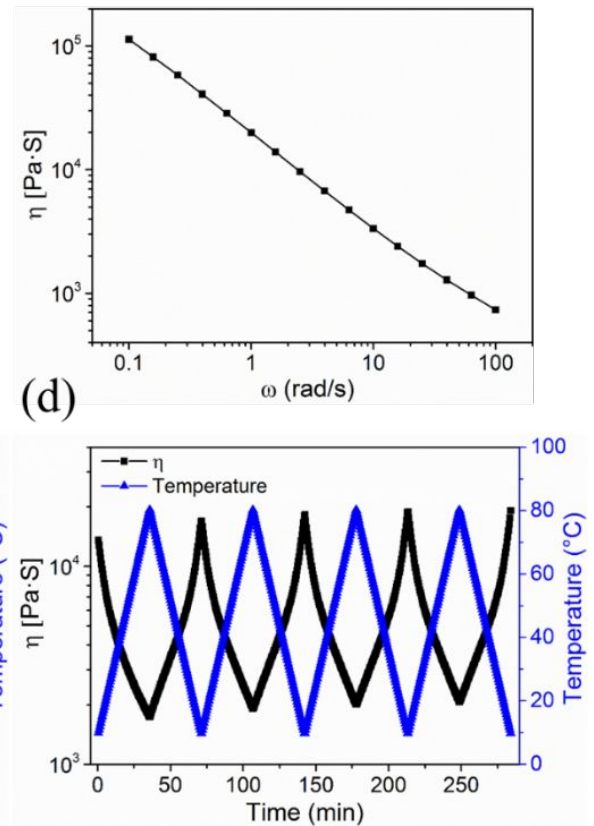

Figure S25. (a) Storage modulus $\left(G^{\prime}\right)$ and loss modulus $\left(G^{\prime} \text { ') values of poly(TA-CA }\right)_{10 / 1}$ on frequency sweep at 25 ${ }^{\circ} \mathrm{C}$; (b) composite viscosity $(\eta)$ value of poly(TA-CA $)_{10 / 1}$ on frequency sweep at $25^{\circ} \mathrm{C}$; (c) $G$ ' and $G$ '” values of poly(TA-CA) $)_{10 / 1}$ at reversible temperature-dependent rheological tests; (d) $\eta$ value of poly(TA-CA $)_{10 / 1}$ at reversible temperature-dependent rheological tests.

(a)

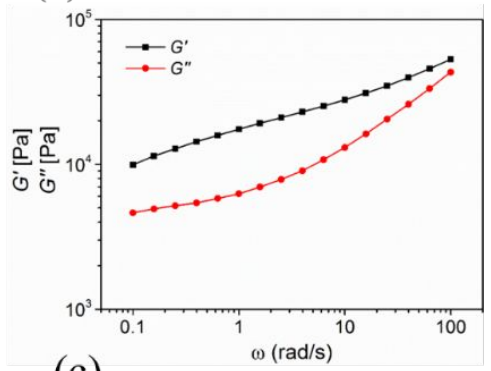

(c)

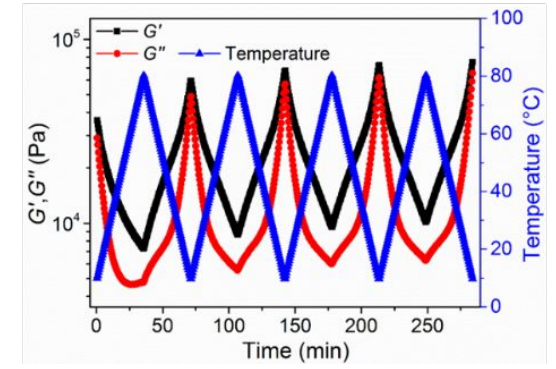

(b)

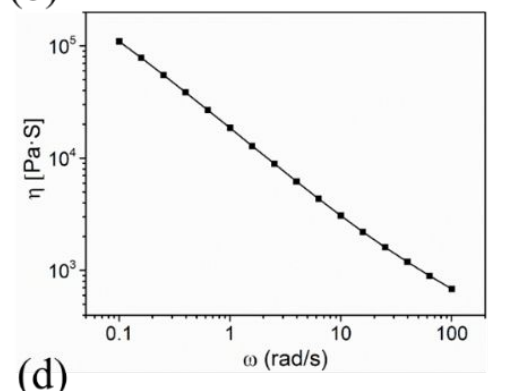

(d)

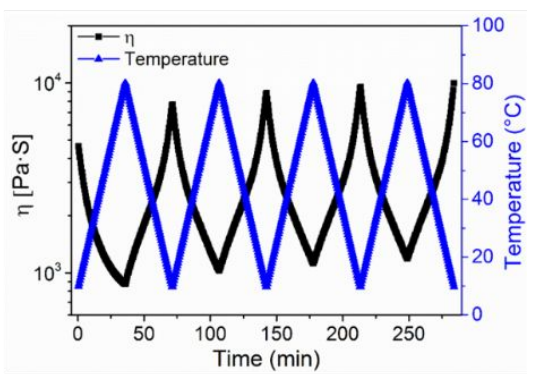

Figure S26. (a) Storage modulus $\left(G^{\prime}\right)$ and loss modulus $\left(G^{\prime \prime}\right)$ values of poly(TA-CA $)_{15 / 1}$ on frequency sweep at 25 ${ }^{\circ} \mathrm{C}$; (b) composite viscosity $(\eta)$ value of poly(TA-CA) $)_{15 / 1}$ on frequency sweep at $25^{\circ} \mathrm{C}$; (c) $G$ ' and $G$ "' values of poly(TA-CA) ${ }_{15 / 1}$ at reversible temperature-dependent rheological tests; (d) $\eta$ value of poly(TA-CA $)_{15 / 1}$ at reversible temperature-dependent rheological tests. 
(a)

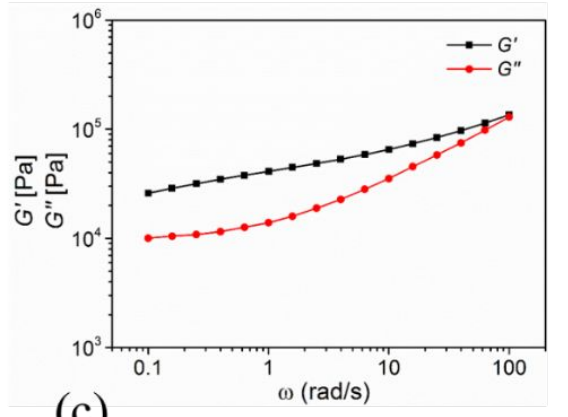

(c)

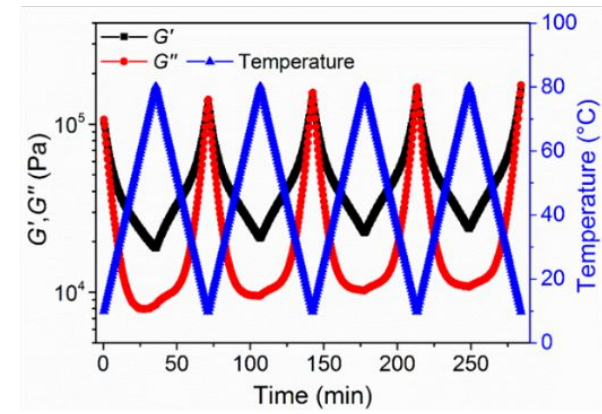

(b)

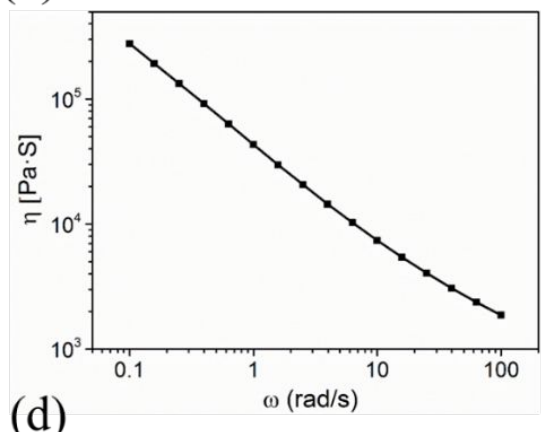

(d)

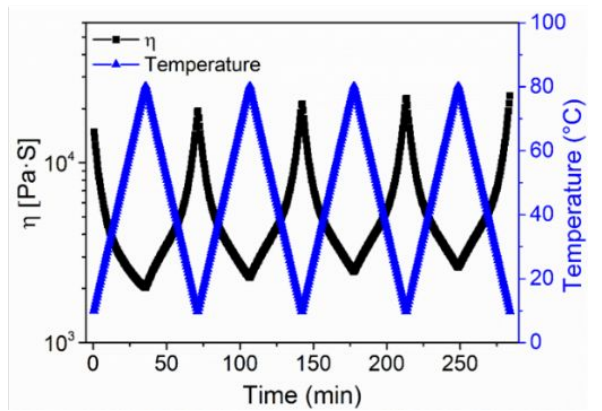

Figure S27. (a) Storage modulus $\left(G^{\prime}\right)$ and loss modulus $\left(G^{\prime \prime}\right)$ values of poly(TA-CA) $)_{20 / 1}$ on frequency sweep at 25 ${ }^{\circ} \mathrm{C}$; (b) composite viscosity $(\eta)$ value of poly(TA-CA $)_{20 / 1}$ on frequency sweep at $25^{\circ} \mathrm{C}$; (c) $G$ ' and $G$ "' values of poly(TA-CA $)_{20 / 1}$ at reversible temperature-dependent rheological tests; (d) $\eta$ value of poly(TA-CA $)_{20 / 1}$ at reversible temperature-dependent rheological tests.

(a)

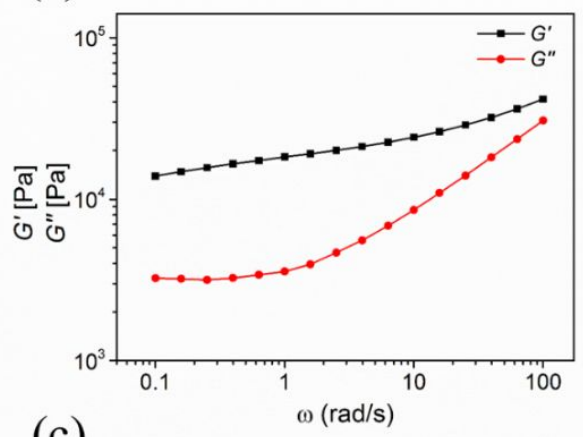

(c)

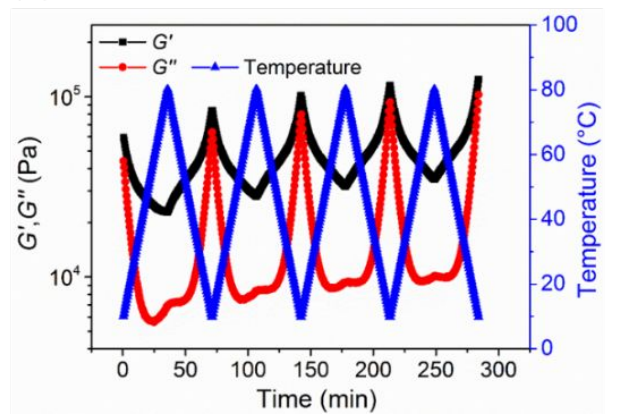

(b)

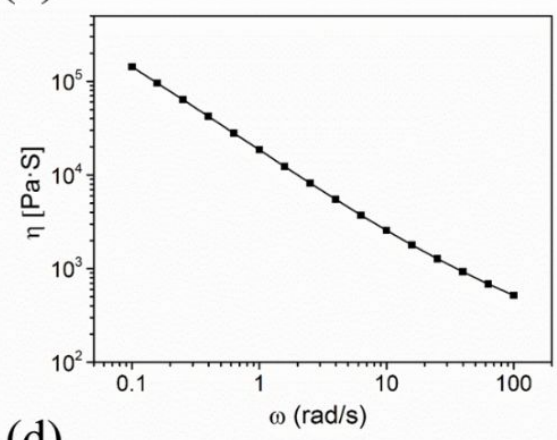

(d)

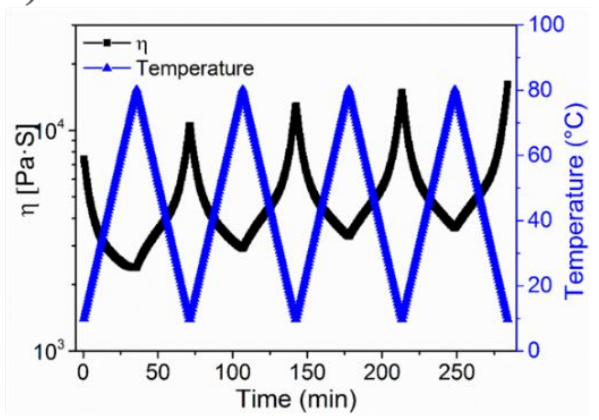

Figure S28. (a) Storage modulus $\left(G^{\prime}\right)$ and loss modulus $\left(G^{\prime \prime}\right)$ values of poly(TA) on frequency sweep at $25^{\circ} \mathrm{C}$; (b) composite viscosity $(\eta)$ value of poly(TA) on frequency sweep at $25^{\circ} \mathrm{C}$; (c) $G^{\prime}$ and $G$ ", values of poly(TA) at reversible temperature-dependent rheological tests; (d) $\eta$ value of poly(TA) at reversible temperature-dependent rheological tests. 


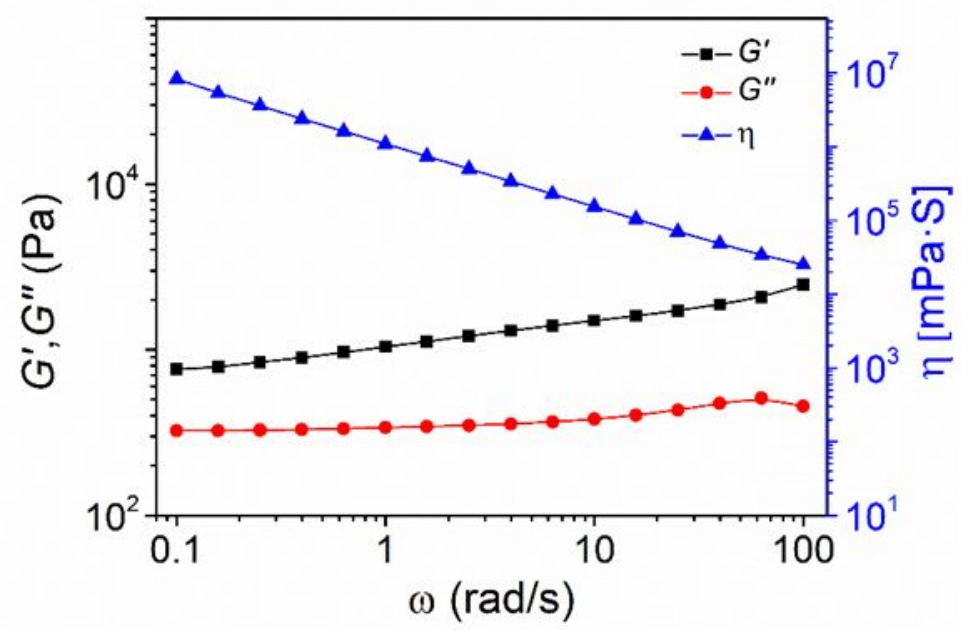

Figure S29. Storage modulus $\left(G^{\prime}\right)$, loss modulus $\left(G^{\prime}\right)$, and viscosity $(\eta)$ values of poly(TA-CA $)_{5 / 1}$ (after solvent exchange) on frequency sweep at $25^{\circ} \mathrm{C}$.

(a)

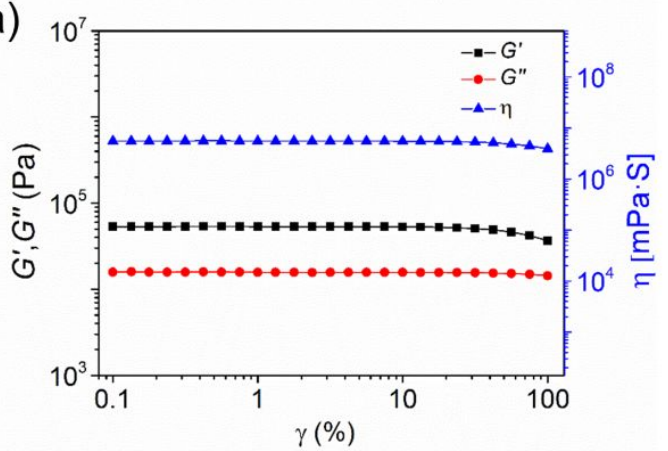

(b)

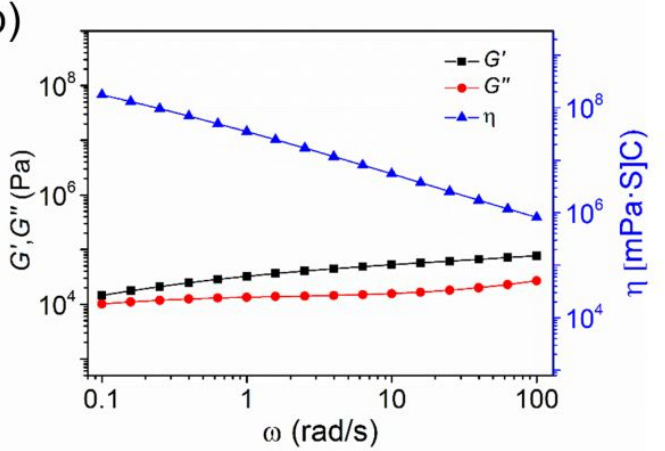

Figure S30. (a) Storage modulus $\left(G^{\prime}\right)$, loss modulus $\left(G^{\prime}\right)$, and viscosity $(\eta)$ values of dry poly(TA-CA $)_{5 / 1}$ (after solvent exchange) on strain sweep at $25^{\circ} \mathrm{C}$; (b) storage modulus $\left(G^{\prime}\right)$, loss modulus $\left(G^{\prime \prime}\right)$ and viscosity $(\eta)$ values of dry poly(TA-CA) $)_{5 / 1}$ (after solvent exchange) on frequency sweep at $25^{\circ} \mathrm{C}$.

\section{Environmental Scanning Electron Microscopy (ESEM) of poly $(T A-C A)_{5 / 1}$}
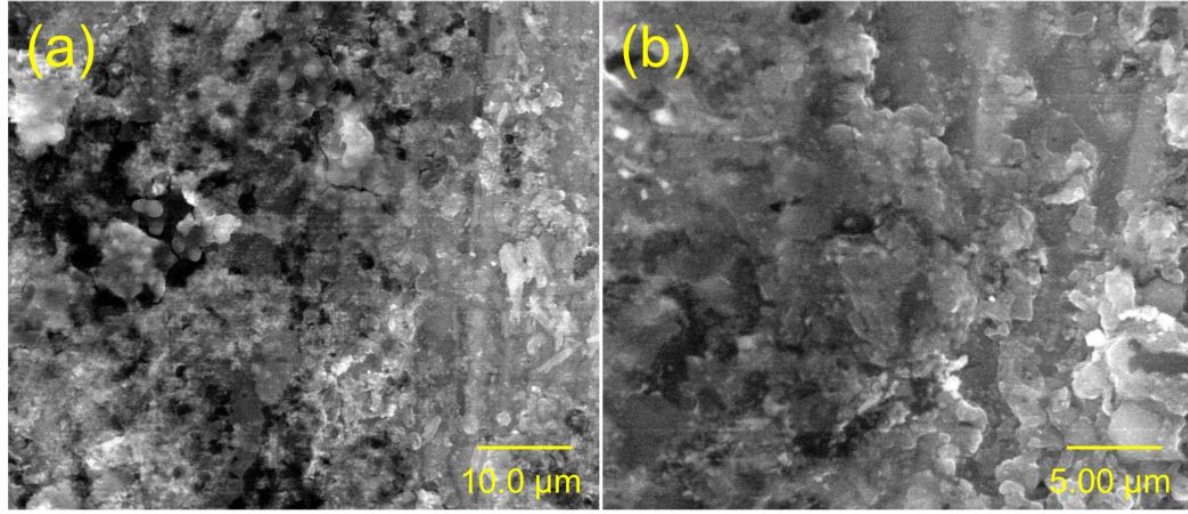

Figure S31. ESEM images of poly(TA-CA) $)_{5 / 1}$ after solvent exchange (a) and (b). 


\section{Characterizations of hydrogel and porcine skin}

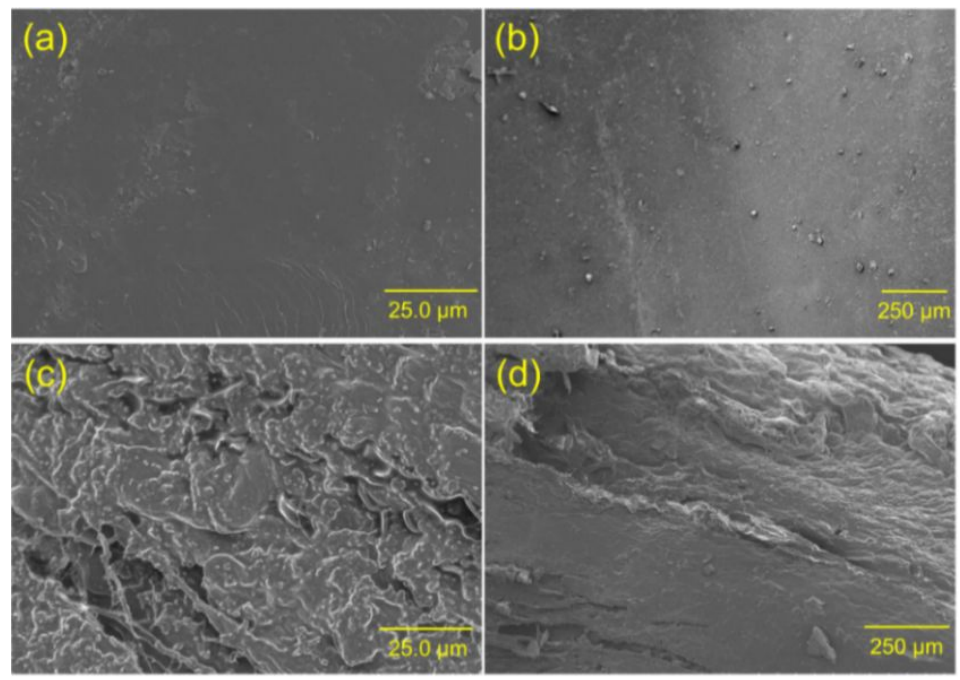

Figure S32. SEM images of (a, b) hydrogel and (c, d) porcine skin.

(a)

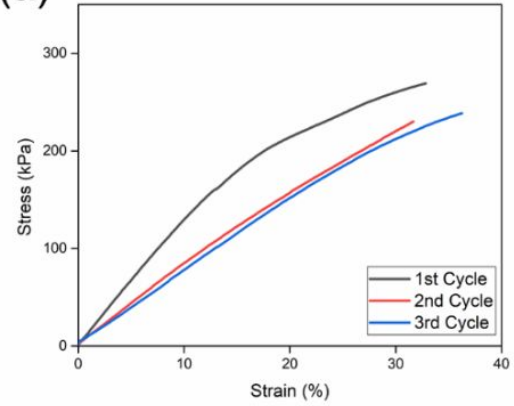

(b)

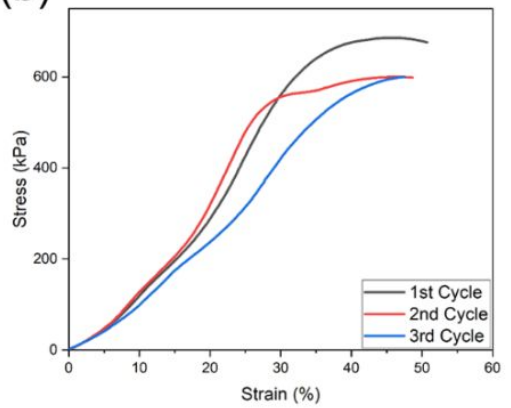

Figure S33. Stress-strain curves of (a) hydrogel and (b) porcine skin.

The stress-strain curves demonstrate that hydrogel and porcine skin are soft substrates.
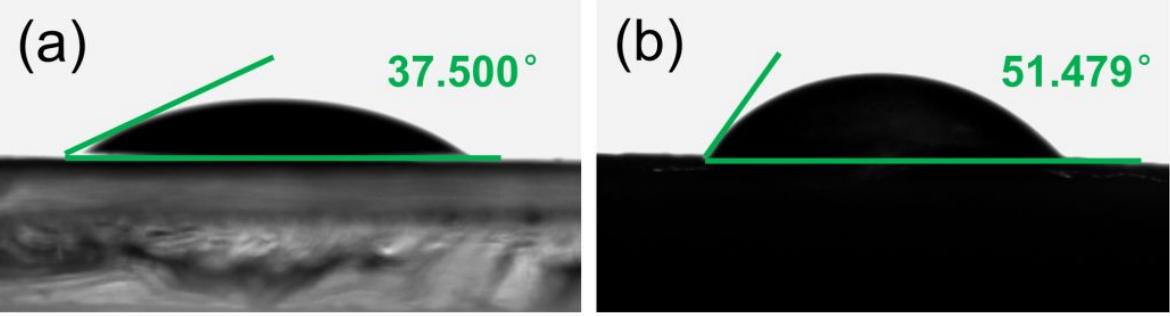

Figure S34. Contact angles of (a) hydrogel and (b) porcine skin. 


\section{Macroscopic view of poly $(T A-C A)_{5 / 1}$}

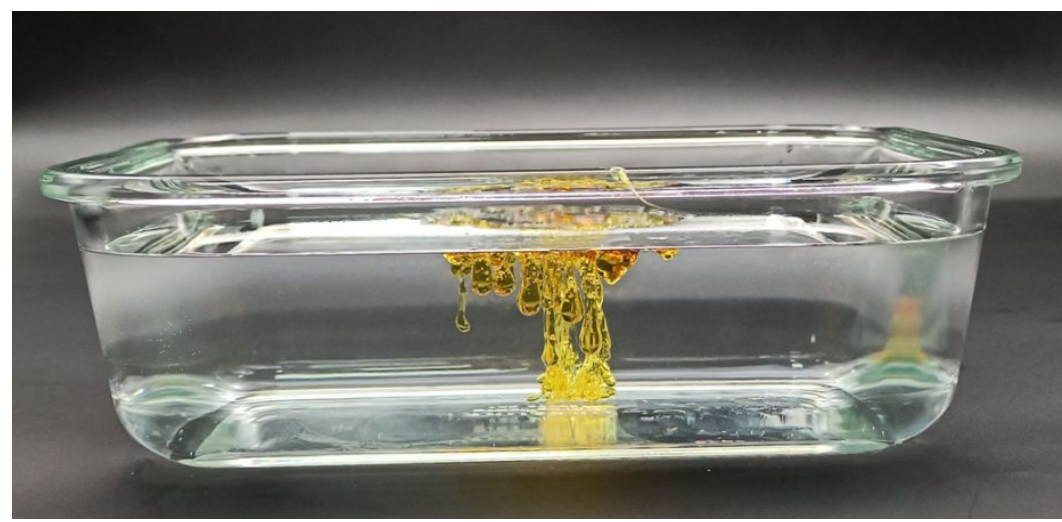

Figure S35. Photograph of hot poly(TA-CA) $)_{5 / 1}$ pouring into water (water temperature was around $20^{\circ} \mathrm{C}$ ).
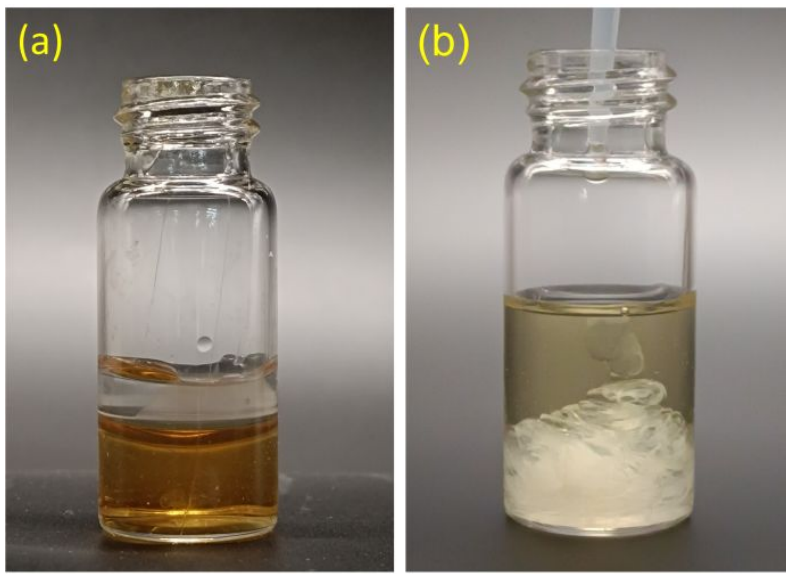

Figure S36. Solvent exchange behavior of poly(TA-CA) $)_{5 / 1}$ at different concentrations: (a) $50 \mathrm{wt} \%$; (b) $25 \mathrm{wt} \%$. After stirring, viscous adhesive can be formed in (a).

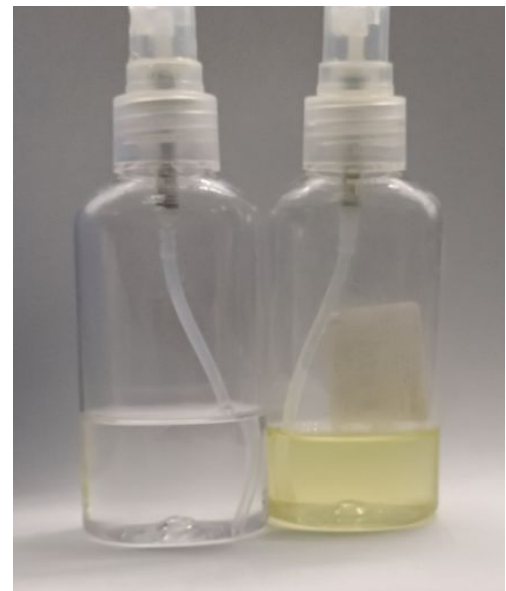

Figure S37. Water (left) and poly(TA-CA) $)_{5 / 1}$ ethanol solution (right) used in adhesion tests. 


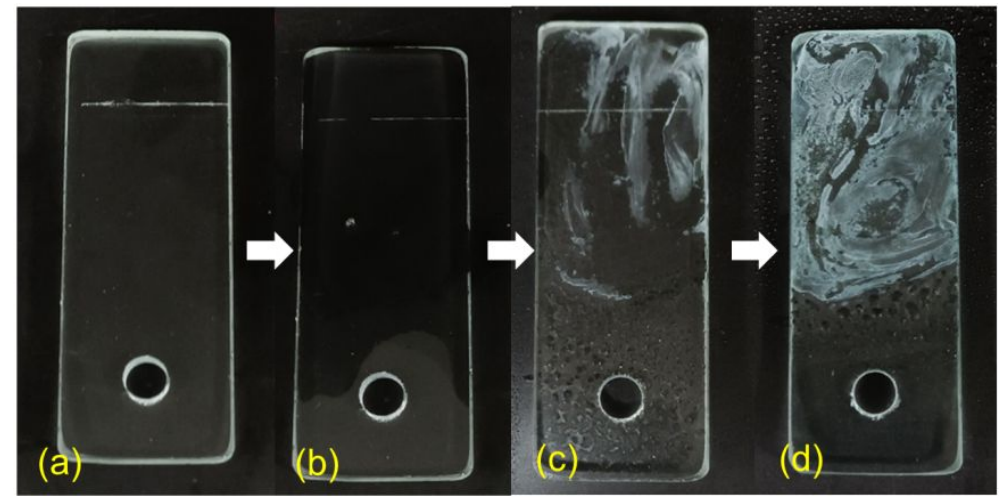

Figure S38. Solvent exchange process of poly(TA-CA) $)_{5 / 1}$ : (a) glass substrate; (b) spraying with poly(TA-CA) $)_{5 / 1}$ ethanol solution (25 wt\%); (c-d) spraying with water.
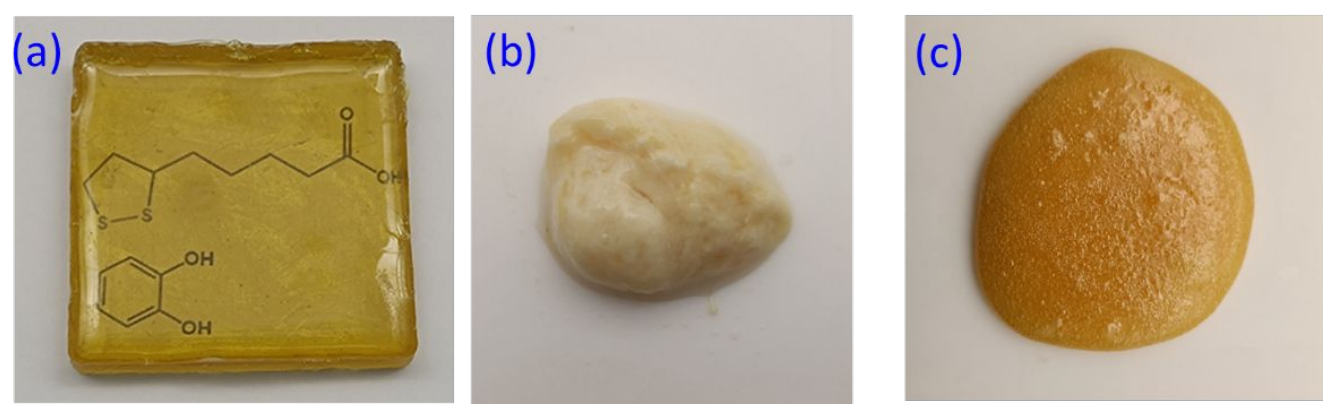

Figure S39. Photographs of poly(TA-CA) $)_{5 / 1}$ : (a) before solvent exchange; (b) after solvent exchange; (c) after solvent exchange (dried).

Here "dried" indicates the sample was dried and the solvent was removed.

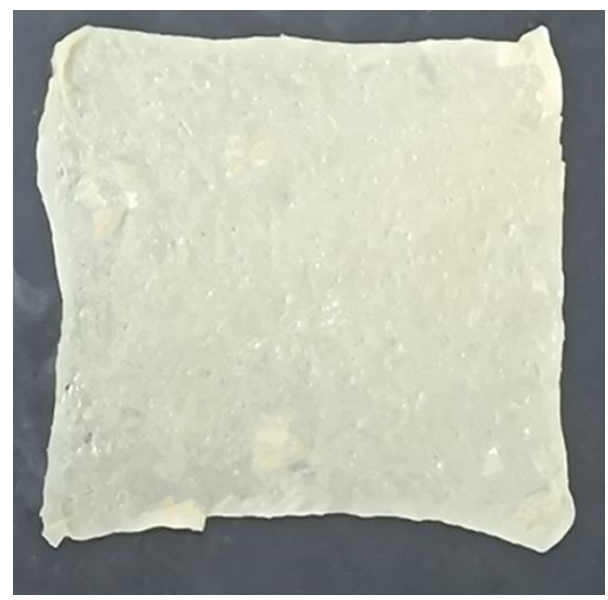

Figure S40. Photograph of poly(TA-CA $)_{5 / 1}$ membrane obtained by water-ethanol exchange $\left(100 \times 100 \times 0.5 \mathrm{~mm}^{3}\right)$. 

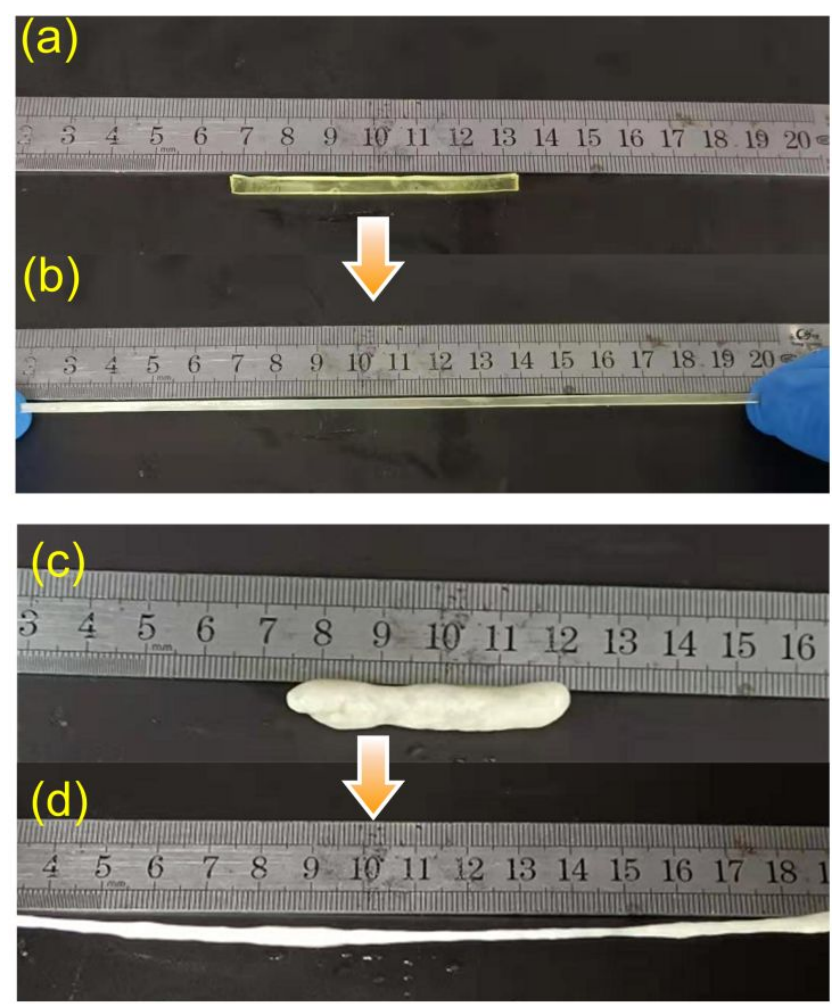

Figure S41. Photographs of poly(TA-CA) $)_{5 / 1}$ : $(\mathrm{a}, \mathrm{b})$ before solvent exchange; $(\mathrm{c}, \mathrm{d})$ after solvent exchange.
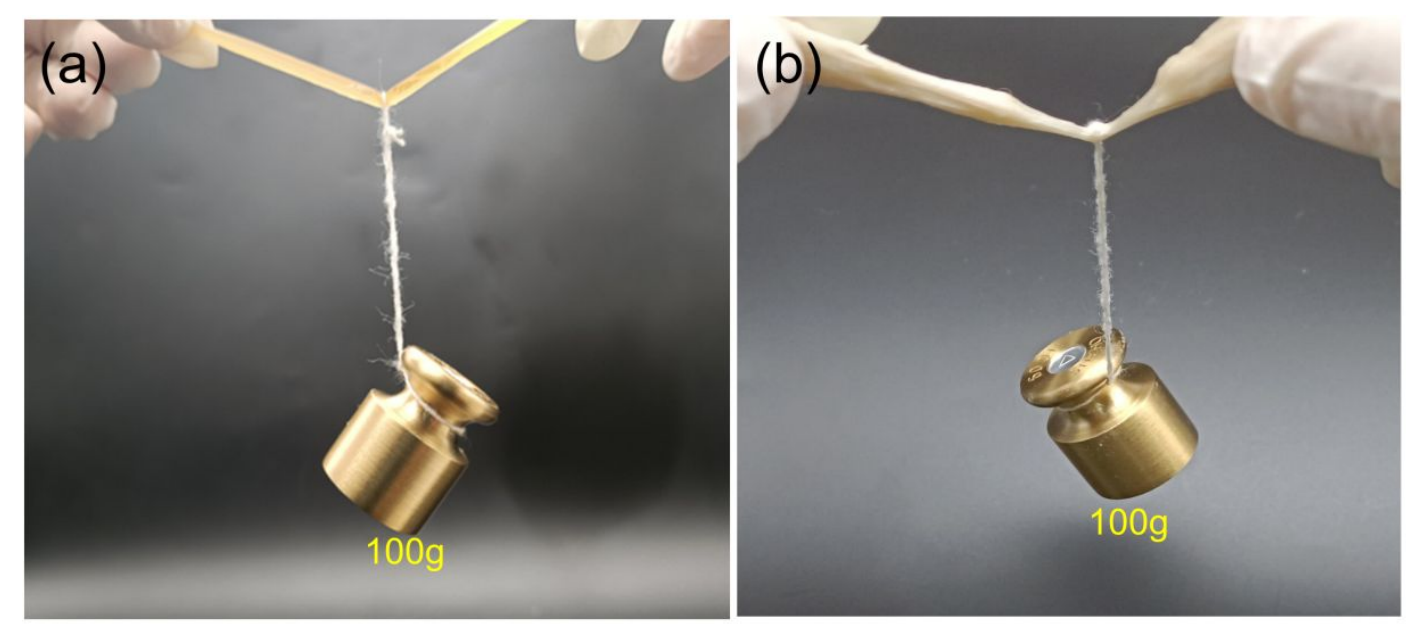

Figure S42. Photographs of poly(TA-CA) $)_{5 / 1}$ hanging a load: (a) before solvent exchange; (b) after solvent exchange.

Good mechanical properties, including elasticity, were observed from poly(TA-CA $)_{5 / 1}$ after solvent exchange. 
14. Stress-strain curve of poly $(T A-C A)_{5 / 1}$ and adhesion behavior after solvent exchange

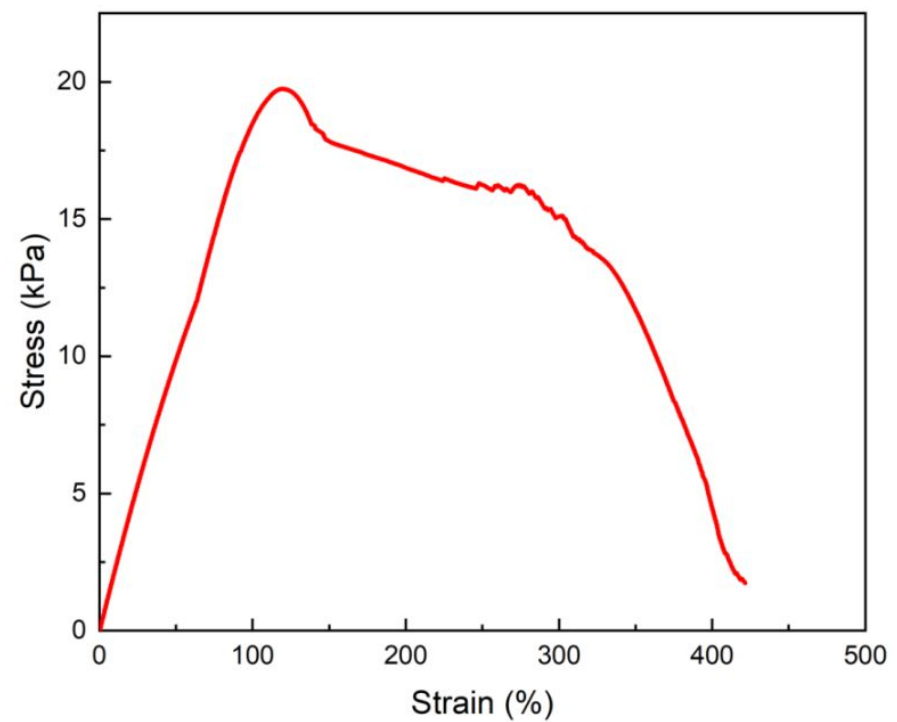

Figure S43. Stress-strain curve of poly(TA-CA) $)_{5 / 1}$ (after solvent exchange).

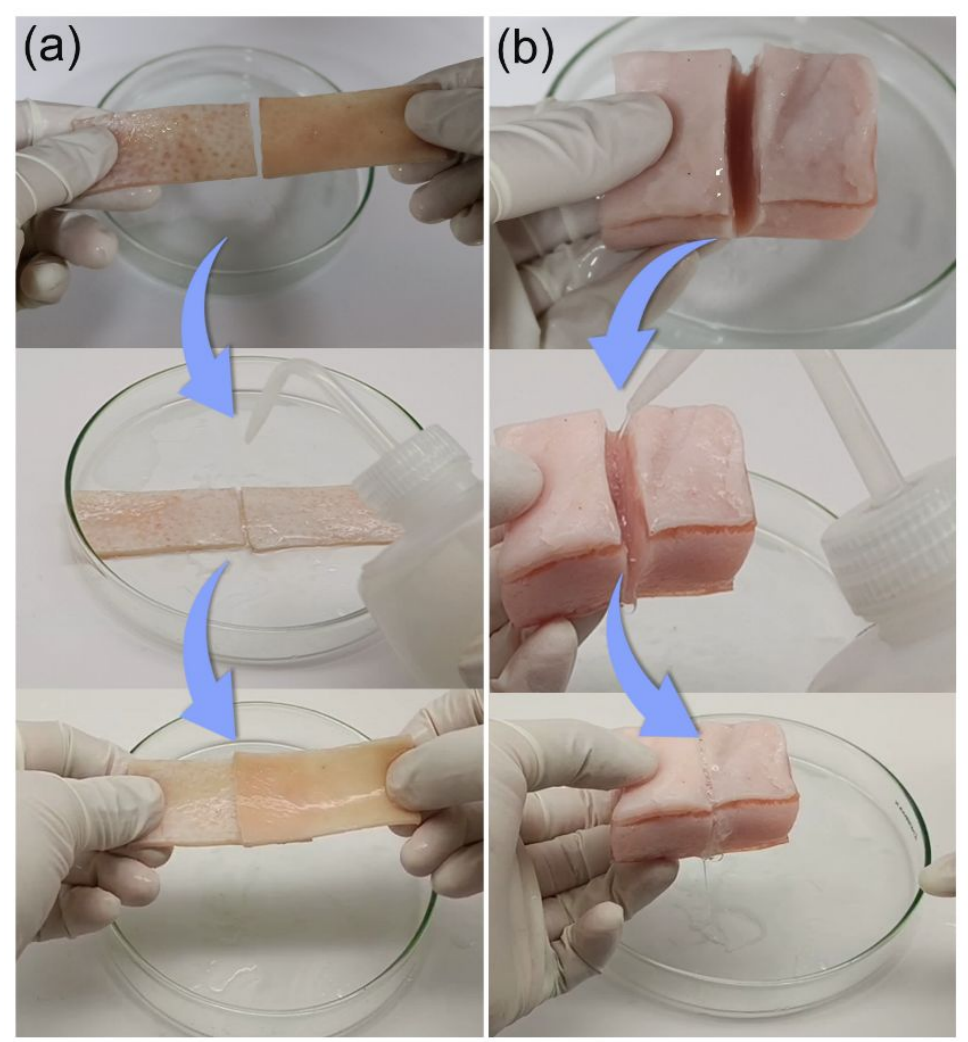

Figure S44. Macroscopic adhesion of poly(TA-CA) $)_{5 / 1}$ on soft substrates via solvent exchange method: (a) porcine skin; (b) porcine tissue. 


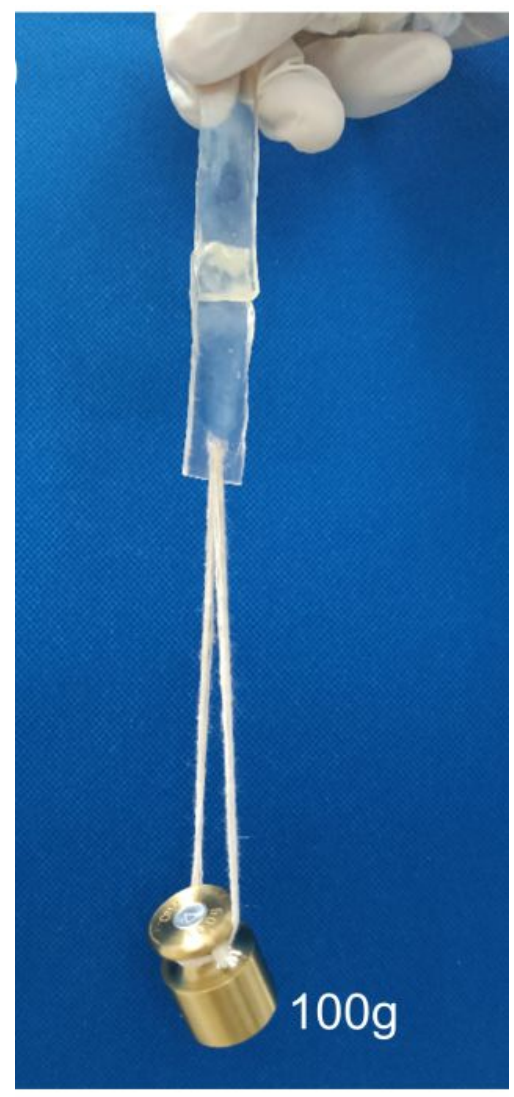

Figure S45. Macroscopic adhesion behavior of poly(TA-CA) $)_{5 / 1}$ on hydrogel via solvent exchange method (the adhesion area is $2.25 \mathrm{~cm}^{2}$ ).

\section{Time-dependent adhesion measurements of poly $(\mathrm{TA}-\mathrm{CA})_{5 / 1}$}

(a)

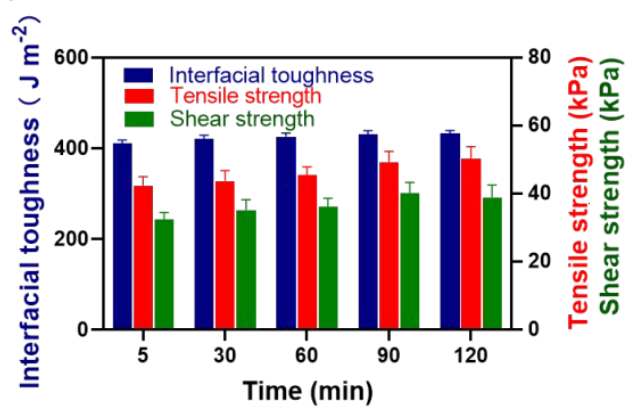

(b)

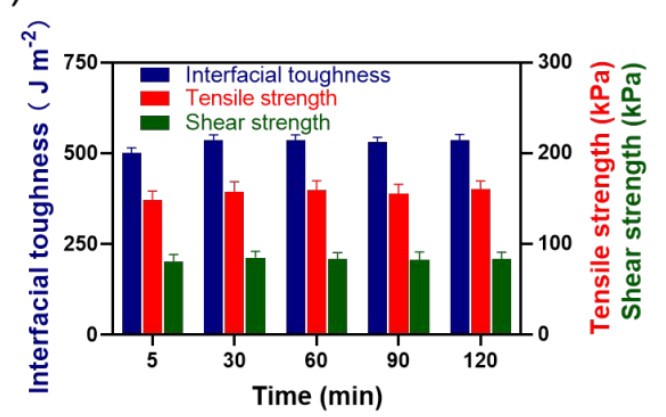

Figure S46. Time-dependent adhesion strengths of poly(TA-CA) $)_{5 / 1}$ by hot melt method: (a) hydrogel; (b) porcine skin.

As shown in Figure S46, poly(TA-CA $)_{5 / 1}$ exhibits good adhesion just after the adhesion process by hot-melt. Only silght changes of the adhesion strength were observed at different adhesion time. 


\section{Adhesion measurements of poly(TA-CA)s via solvent exchange}

(a)

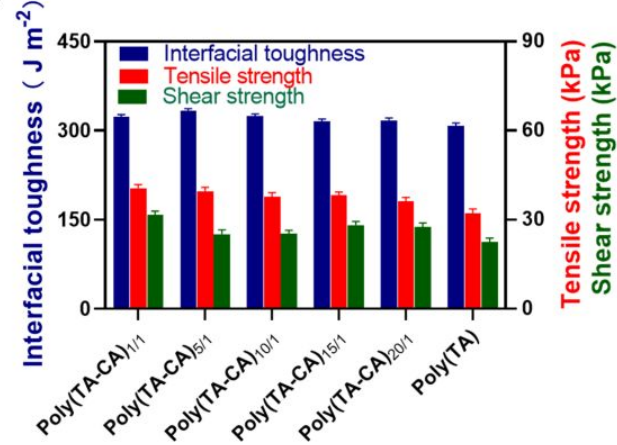

(b)

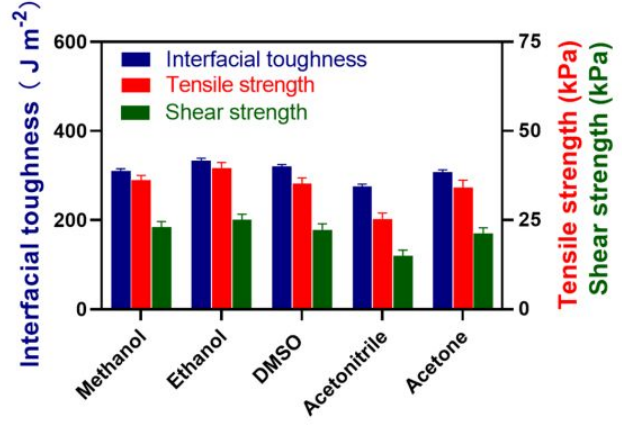

Figure S47. Adhesion strengths of poly(TA-CA)s via solvent exchange method. (a) Interfacial toughness, shear strength, and tensile strength of poly(TA-CA)s on hydrogel (measured $2 \mathrm{~h}$ after adhesion); (b) Solvent-dependent interfacial toughness, shear strength, and tensile strength of poly(TA-CA) $)_{5 / 1}$ to hydrogel (measured $2 \mathrm{~h}$ after adhesion).

\section{Adhesion measurements of phenols as noncovalent crosslinkers}

(a)

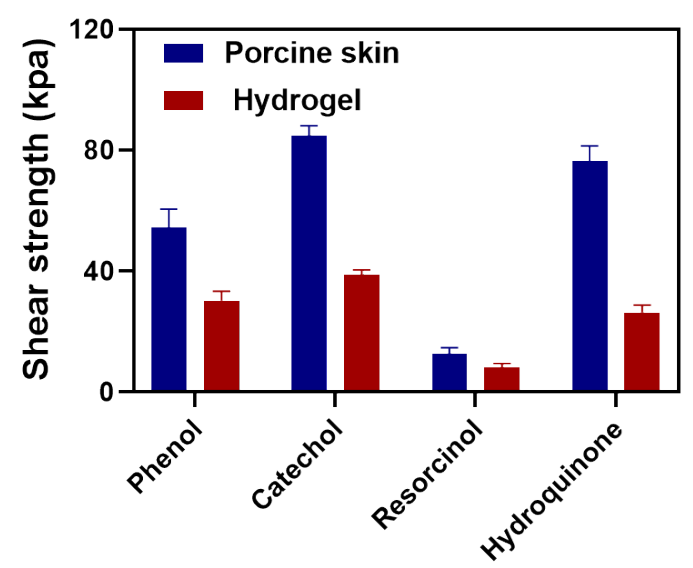

(b)

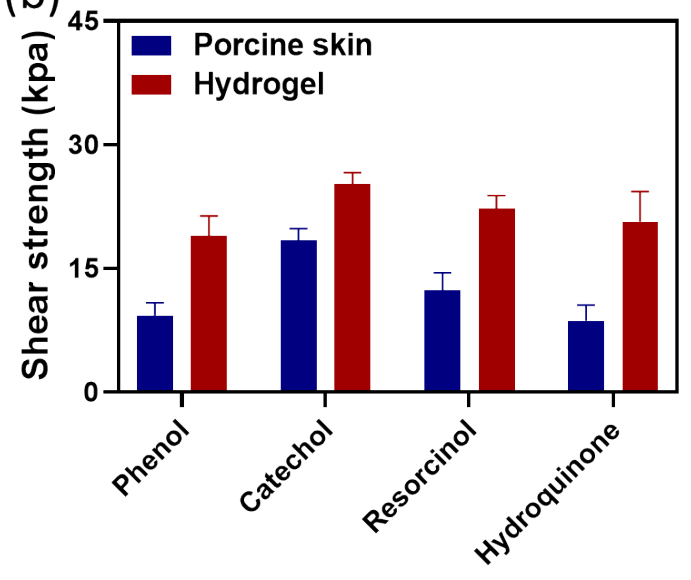

Figure S48. Adhesion strengths of phenols as noncovalent crosslinkers (the molar ratio of TA and phenols is 5:1). (a) Shear strength of phenols as noncovalent crosslinkers on porcine skin and hydrogel (both measured $2 \mathrm{~h}$ after adhesion) by hot melt method; (b) Shear strength of phenols as noncovalent crosslinkers on porcine skin (porcine measured ca. $1 \mathrm{~min}$ after adhesion) and hydrogel (hydrogel measured $2 \mathrm{~h}$ after adhesion) via solvent exchange method.

As shown in Figure S48, the adhesion properties of catechol molecules as non-covalent cross-linkers is better than that of other linkers by both hot-melt and solvent-exchange methods.

\section{Molecular dynamics (MD) simulation calculation}

In order to assess the intermolecular interaction of the poly(TA-CA)s, the cohesive energy density electrostatic (CEDE) was calculated by Molecular Dynamics (MD) Simulation. ${ }^{3}$ The Condensed-Phase Optimized Potentials for Atomistic Simulation Studies (COMPASS) force field 
was used to provide the atomic interactions. Then, the Ewald method was employed for analyzing the Coulomb interactions interactions between molecules.

To equilibrate the model, a equilibrate process was followed under constant temperature and constant volume (NPT ensemble) at $298 \mathrm{~K}$ for 5000 ps. During the simulation, Velocity Scale thermostat and Berendsen barostat was applied in the temperature and pressure control, respectively.

In this work, a series of simplified molecular models of poly(TA-CA $)_{5 / 1}$, water, and ethanol were built using Materials Studio (MS) software as shown in Figure 4g and Figure S49, respectively. Five adhesives models were constructed:

( I ) Adhesive model contains 150 thioctic acid molecules, 30 catechol molecules, and 300 ethanol molecules.

( II) Adhesive model contains 150 thioctic acid molecules, 30 catechol molecules, and 900 ethanol molecules.

(III) Adhesive model contains 150 thioctic acid molecules, 30 catechol molecules, 300 ethanol molecules, and 600 water molecules.

(IV) Adhesive model contains 150 thioctic acid molecules and 30 catechol molecules.

(V) Adhesive model contains 150 thioctic acid molecules.

The cohesive energy density electrostatic was calculated according to the following Eqs. (12).

$C E D E=\frac{E_{c o h}}{V} \#(1)$

$$
E_{c o h}=-E_{\text {intre }}=E_{\text {intra }}-E_{\text {total }}
$$

where $E_{\text {coh }}$ is the cohesive energy electrostatic; $V$ is the volume of a system; $\mathrm{E}_{\text {inter }}$ is the total electrostatic energy between all molecules; $E_{\text {intra }}$ is the intramolecular electrostatic energy; $E_{\text {total }}$ is the total electrostatic energy of a system.

Table S2. Cohesive energy density electrostatic of poly(TA-CA)s models at $298 \mathrm{~K}$.

\begin{tabular}{cccccc}
\hline & $\begin{array}{c}\text { TA } \\
(\mathrm{mol})\end{array}$ & $\begin{array}{c}\text { CA } \\
(\mathrm{mol})\end{array}$ & $\begin{array}{c}\text { Ethanol } \\
(\mathrm{mol})\end{array}$ & $\begin{array}{c}\text { Water } \\
(\mathrm{mol})\end{array}$ & $\begin{array}{c}\text { Cohesive energy density } \\
\text { electrostatic }\left(\mathrm{J} / \mathrm{m}^{3}\right)\end{array}$ \\
\hline ( I $)$ & 5 & 1 & 10 & 0 & $3.188 \times 10^{8} \pm 3.041 \times 10^{5}$ \\
(II) & 5 & 1 & 30 & 0 & $4.076 \times 10^{8} \pm 2.559 \times 10^{5}$ \\
(III) & 5 & 1 & 10 & 20 & $7.865 \times 10^{8} \pm 4.483 \times 10^{5}$ \\
(IV) & 5 & 1 & 0 & 0 & $1.654 \times 10^{8} \pm 3.199 \times 10^{5}$ \\
(V) & 1 & 0 & 0 & 0 & $1.406 \times 10^{8} \pm 2.615 \times 10^{5}$ \\
\hline
\end{tabular}


(a)

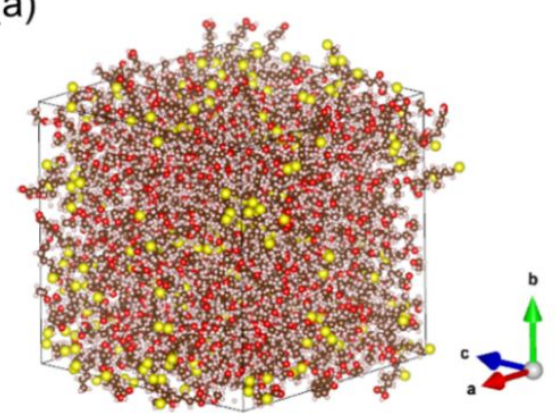

(c)

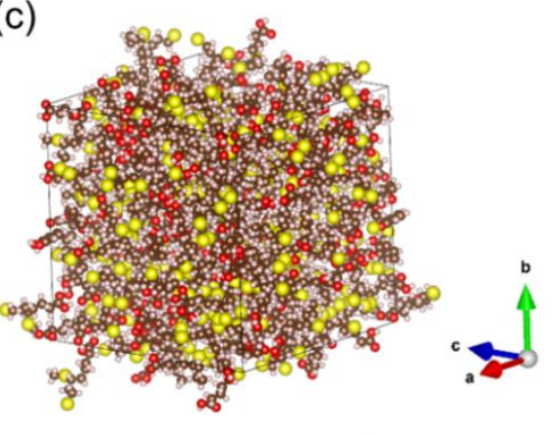

C० Ho (b)

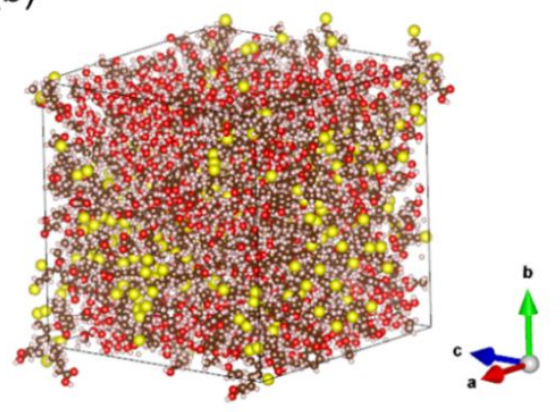

(d)

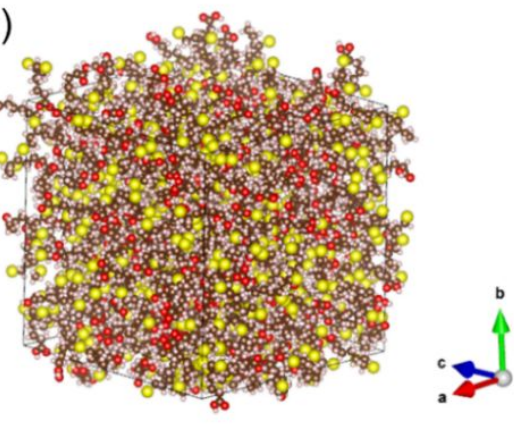

$\mathrm{S}$

Figure S49. Molecular models of ploy(TA-CA) $)_{5 / 1}$, poly(TA), water and ethanol: (a) adhesive model contains 150 thioctic acid molecules, 30 catechol molecules, and 900 ethanol molecules; (b) adhesive model contains 150 thioctic acid molecules, 30 catechol molecules, 300 ethanol molecules, and 600 water molecules; (c) adhesive model contains 150 thioctic acid molecules, and 30 catechol molecules; (d) adhesive model contains 150 thioctic acid molecules. 


\section{Temperature of porcine skin by hot-melt method}

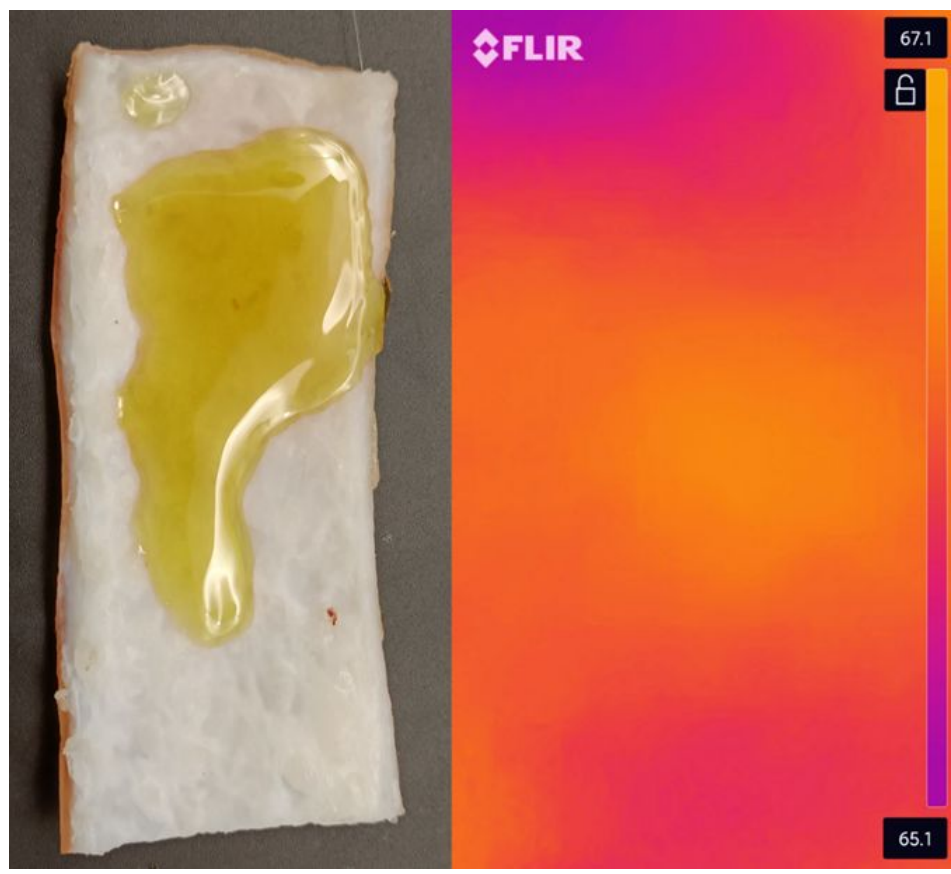

Figure S50. Temperature of porcine skin adhered by hot-melt method with poly(TA-CA) $)_{5 / 1}$.

\section{Residual catechol after solvent exchange}

The loss of catechol in the solvent exchange process was analyzed by HPLC (Table S3). The samples were analyzed by a P230II HPLC system (Dalian Elite Analytical Instruments Co., Ltd.). A Syncronis $\mathrm{C}_{18}$ chromatographic column $(250 \times 4.6 \mathrm{~mm}$, I.D. $5 \mu \mathrm{m})$ was used as the stationary phase; methanol/acetic acid $(0.2 \mathrm{VOL} \%)=50: 50(\mathrm{~V} / \mathrm{V})$ was used as the mobile phase; the detection wavelength was $277 \mathrm{~nm}$; the temperature was $30^{\circ} \mathrm{C}$; the flow rate was $0.9 \mathrm{~mL} \mathrm{~min}^{-1}$, and the injection volume was $20 \mu \mathrm{L}$.

Table S3. Residual catechol after solvent exchange.

\begin{tabular}{cc}
\hline Sample & $\begin{array}{r}\text { Residual catechol after solvent } \\
\text { exchange }(\%)\end{array}$ \\
\hline Poly(TA-CA $)_{1 / 1}$ & 9.98 \\
${\text { Poly }(\text { TA-CA })_{5 / 1}}$ & 6.14 \\
Poly $(\text { TA-CA })_{10 / 1}$ & 5.94 \\
Poly(TA-CA $)_{15 / 1}$ & 4.55 \\
${\text { Poly }(\text { TA-CA })_{20 / 1}}$ & 4.83 \\
\hline
\end{tabular}




\section{Video}

Video S1. Water was added into poly(TA-CA $)_{5 / 1}$ ethanol solution.

Video S2. Tensile of poly(TA-CA $)_{5 / 1}$ after solvent exchange.

Video S3. Adhesion process of porcine skin with poly(TA-CA $)_{5 / 1}$ via solvent exchange.

\section{Reference}

(1) Kisanuki, A., Kimpara, Y., Oikado, Y., Kado, N., Matsumoto, M., Endo, K. RingOpening Polymerization of Lipoic Acid and Characterization of the Polymer. J. Polym. Sci. Pol. Chem 2010, 48, 5247-5253.

(2) Shi, C.-Y., Zhang, Q., Wang, B.-S., Chen, M., Qu, D.-H. Intrinsically Photopolymerizable Dynamic Polymers Derived from a Natural Small Molecule. ACS Appl. Mater. Interfaces 2021, 13, 44860-44867.

(3) Long, Z., You, L., Tang, X., Ma, W., Ding, Y., Xu, F. Analysis of Interfacial Adhesion Properties of Nano-Silica Modified Asphalt Mixtures Using Molecular Dynamics Simulation. Constr. Build. Mater. 2020, 255, 119354. 